\title{
The sulfonate group as a ligand: a fine balance between hydrogen bonding and metal ion coordination in uranyl ion complexes $\dagger$
}

\author{
Pierre Thuéry, ${ }^{* a}{ }^{\mathrm{a}}$ Youssef Atoini ${ }^{\mathrm{b}}$ and Jack Harrowfield ${ }^{* \mathrm{~b}}$
}

Nine uranyl ion complexes have been synthesized using two kinds of sulfonate-containing ligands, i.e. 2-, 3- and 4-sulfobenzoic acids (2-, 3- and 4- $\mathrm{SBH}_{2}$ ), which include additional carboxylic donors, and $p$ sulfonatocalix[4]arene $\left(\mathrm{H}_{8} \mathrm{C} 4 \mathrm{~S}\right)$, with additional phenolic groups, and $[\mathrm{Ni}(\mathrm{cyclam})]^{2+},\left[\mathrm{Cu}\left(R, S-\mathrm{Me}_{6} \mathrm{cyclam}\right)\right]^{2+}$ or $\mathrm{PPh}_{4}{ }^{+}$as counterions. $[\mathrm{Ni}($ cyclam $)]\left[\mathrm{UO}_{2}(4-\mathrm{SB})_{2}\left(\mathrm{H}_{2} \mathrm{O}\right)_{2}\right] \cdot 2 \mathrm{CH}_{3} \mathrm{CN}(\mathbf{1})$ and $[\mathrm{Ni}(\mathrm{cyclam})]\left[\mathrm{UO}_{2}(3-\mathrm{SB})_{2}\left(\mathrm{H}_{2} \mathrm{O}\right)_{2}\right](2)$ are molecular species in which only the carboxylate groups are coordinated to uranyl, the sulfonate groups being essentially hydrogen bond acceptors. In contrast, uranyl $\kappa^{1}-O(S) ; \kappa^{1}-O(C)$-chelation is found in the four complexes involving 2-SB ${ }^{2-}$, different bridging interactions producing diverse geometries. $\left[\mathrm{UO}_{2}(2-\mathrm{SB})_{2} \mathrm{Ni}(\right.$ cyclam $\left.)\right] \cdot \mathrm{H}_{2} \mathrm{O}(3)$ crystallizes as a two-dimensional (2D) assembly with fes topology, in which uranyl ion dimeric subunits are bridged by six-coordinate $\mathrm{Ni}^{\mathrm{II}}$ cations. Complexes $\left[\mathrm{UO}_{2}(2-\mathrm{SB})_{2} \mathrm{Cu}\left(R, S-\mathrm{Me}_{6} \mathrm{cyclam}\right)\right]_{2} \cdot 2 \mathrm{H}_{2} \mathrm{O}(4)$ and $\left[\left(\mathrm{UO}_{2}\right)_{2}(2-\right.$ $\mathrm{SB})_{2}\left(\mathrm{C}_{2} \mathrm{O}_{4}\right) \mathrm{Cu}\left(R, S-\mathrm{Me}_{6}\right.$ cyclam)] (5), obtained together from the same solution, are a molecular tetranuclear complex and a 2D species with fes topology, respectively, depending on the coordination number, 5 or 6 , of the $\mathrm{Cu}^{\mathrm{II}}$ cation. The complex $\left[\mathrm{PPh}_{4}\right]_{2}\left[\left(\mathrm{UO}_{2}\right)_{2}(2-\mathrm{SB})_{3}\left(\mathrm{H}_{2} \mathrm{O}\right)\right] \cdot \mathrm{H}_{2} \mathrm{O}$ (6) is a one-dimensional (1D), ribbon-like coordination polymer with a layered packing of alternate cationic and anionic sheets. No heterometallic complex was obtained with $\mathrm{H}_{8} \mathrm{C} 4 \mathrm{~S}$, but the copper-only compound $\left[\left\{\mathrm{Cu}\left(R, S-\mathrm{Me}_{6} \mathrm{cyclam}\right)\right\}_{5}\left(\mathrm{H}_{3} \mathrm{C} 4 \mathrm{~S}\right)_{2}\right] \cdot 17 \mathrm{H}_{2} \mathrm{O}(7)$ displays mixed coordination/hydrogen bonding association of the copper azamacrocycle complex to the phenolic groups. The complexes $\left[\mathrm{PPh}_{4}\right]_{5}\left[\mathrm{UO}_{2}\left(\mathrm{H}_{4} \mathrm{C} 4 \mathrm{~S}\right)\left(\mathrm{H}_{2} \mathrm{O}\right)_{4}\right]\left[\mathrm{UO}_{2}\left(\mathrm{H}_{3} \mathrm{C} 4 \mathrm{~S}\right)\left(\mathrm{H}_{2} \mathrm{O}\right)_{4}\right] \cdot 14 \mathrm{H}_{2} \mathrm{O}(\mathbf{8})$ and $\left[\mathrm{PPh}_{4}\right]_{3}\left[\mathrm{UO}_{2}\left(\mathrm{H}_{3} \mathrm{C} 4 \mathrm{~S}\right)\left(\mathrm{H}_{2} \mathrm{O}\right)_{3}\right]$. $9 \mathrm{H}_{2} \mathrm{O}(9)$ were crystallized from the same solution and are a molecular complex and a 1D polymer, respectively, with monodentate sulfonate coordination to uranyl, while $\left[\mathrm{PPh}_{4}\right]_{2}\left[\mathrm{UO}_{2}\left(\mathrm{H}_{4} \mathrm{C} 4 \mathrm{~S}\right)\left(\mathrm{H}_{2} \mathrm{O}\right)_{3}\right] \cdot 11 \mathrm{H}_{2} \mathrm{O}(\mathbf{1 0})$ is also a $1 \mathrm{D}$ polymer. The anionic complexes in the last three complexes form layers (9) or double layers (8 and 10) separated from one another by hydrophobic layers of $\mathrm{PPh}_{4}{ }^{+}$cations. The balance between coordination and hydrogen bonding interactions with the macrocyclic ligands provides an indication of the energy of the sulfonate coordinate bond. Complex $\mathbf{6}$ is the only luminescent species in this series, albeit with a low quantum yield of $3 \%$, and its emission spectrum is typical of a uranyl complex with five equatorial donors.

${ }^{a}$ NIMBE, CEA, CNRS, Université Paris-Saclay, CEA Saclay, 91191 Gif-sur-Yvette, France; E-mail: pierre.thuery@cea.fr

${ }^{b} I S I S$, Université de Strasbourg, 8 allée Gaspard Monge, 67083 Strasbourg, France; E-mail: harrowfield@unistra.fr

$\dagger$ Electronic Supplementary Information (ESI) available: Tables of crystal data, atomic positions and displacement parameters, anisotropic displacement parameters, and bond lengths and bond angles in CIF format. 


\section{Introduction}

Sulfonates, $\mathrm{RSO}_{3}{ }^{-}$, show a diverse solid state structural chemistry of their metal ion complexes, with coordination modes involving 1, 2 or 3 oxygen donors in simple or bridging arrangements being well-characterized. ${ }^{1-5}$ In part, this diversity reflects the sensitivity of sulfonate- $O$ as a donor to the nature of the substituent group R, the trifluoromethanesulfonate (triflate) anion, for example, as the conjugate base of an extremely strong acid $\left(\mathrm{p} K_{\mathrm{a}}-15\right)$, being a much weaker base than a simple species with an aromatic substituent such as $p$-toluenesulfonate (conjugate acid $\left.\mathrm{p} K_{\mathrm{a}}-6.5\right)$, which in turn is considerably less basic than an aliphatic derivative such as methanesulfonate (conjugate acid $\left.\mathrm{p} K_{\mathrm{a}}-1.9\right) .{ }^{6}$ Even so, all sulfonates must be regarded as rather weak ligands, ${ }^{1}$ and in the crystal structures of many metal sulfonates it is rather commonly found that the sulfonate groups are not directly coordinated to the metal ion and instead are hydrogen bonded to ligands which are in the primary coordination sphere of that cation. Numerous examples of this behaviour are found in the crystal structures of lanthanide ion complexes of sulfonatocalixarenes, leading to the identification of multiple coordination spheres (including the calixarene cavity) about the metal ions. ${ }^{5}$ Where direct coordination has been observed in these systems, it most often involves just one $O$-donor of the sulfonate group, despite the fact that a ligand capable of small chelate ring formation might be expected to bind in this fashion to a large metal $\operatorname{ion}^{7}$ such as an $\mathrm{Ln}^{\mathrm{III}}$ species (and as is known with $\mathrm{Pb}^{\mathrm{II}}$, for example $^{8}$ ). Indeed, in uranyl and mixed uranyl-lanthanide complexes of $p$ sulfonatocalix[4]arene, chelation of a sulfonate group is observed but only on a uranyl centre, ${ }^{9}$ being perhaps an index of the greater Lewis acidity of $\mathrm{U}^{\mathrm{VI}}$ compared to that of $\mathrm{Ln}^{\mathrm{III}}$. It is true, however, that this is a rare case of $\kappa^{2} O, O^{\prime}$ sulfonate chelation, with $\kappa^{1} O$ or $\mu_{2}-\kappa^{1} O ; \kappa^{1} O^{\prime}$ binding modes being of far more frequent occurrence in the relatively limited number of known uranyl

sulfonate structures, ${ }^{10-23}$ although not all of these involve ligands in which sulfonate groups are the only functionality. In extension of our studies of the influence of large complex cations 
upon the crystal structure of anionic uranyl ion complexes and coordination frameworks, ${ }^{24-29}$ a field undergoing considerable expansion, ${ }^{30-34}$ therefore, we have sought to define the influence of such cations on the structure of complexes formed with a variety of ligands incorporating sulfonate donors, a study which has confirmed the rarity of sulfonate chelation to uranyl ion but which has also provided indication of the energy of sulfonate hydrogen bonding interactions, widely studied in systems not containing metal ions, ${ }^{1,35,36}$ which compete with metal ion coordination.

Two families of sulfonate-containing ligands have been used in this work. The first comprises the 2-, 3- and 4-sulfobenzoates (2-, 3- and 4-SB ${ }^{2-}$ ) which include both a carboxylate and a sulfonate group in different relative positions, and have previously been used in the synthesis of several uranyl ion complexes, ${ }^{15,18,21}$ most of them (16 cases) involving the 2substituted derivative, and only one and two with the 3- and 4-substituted ones, respectively. Six new uranyl ion complexes with these ligands (among which four include 2-SB ${ }^{2-}$ ), involving either $[\mathrm{Ni}(\text { cyclam })]^{2+},\left[\mathrm{Cu}\left(R, S-\mathrm{Me}_{6} \text { cyclam }\right)\right]^{2+}$ or $\mathrm{PPh}_{4}{ }^{+}$as counterions $($cyclam $=1,4,8,11$-tetraazacyclotetradecane and $R, S$-Me ${ }_{6}$ cyclam (meso isomer) $=7(R), 14(S)-5,5,7,12,12,14-$ hexamethylcyclam), have been synthesized and are described herein. The other ligand used is the previously mentioned $p$-sulfonatocalix[4]arene $\left(\mathrm{H}_{8} \mathrm{C} 4 \mathrm{~S}\right)$, for which three uranyl complexes with $\mathrm{PPh}_{4}{ }^{+}$counterions have been obtained, as well as a complex with $\left[\mathrm{Cu}\left(R, S-\mathrm{Me}_{6} \text { cyclam }\right)\right]^{2+}$ only. Although these two families of ligands are widely different, the results reported here, in addition to those previously described, allow an assessment of the proclivities of sulfonate ligands in their behaviour toward uranyl cations. 


\section{Experimental}

\section{Synthesis}

Caution! Uranium is a radioactive and chemically toxic element, and uranium-containing samples must be handled with suitable care and protection.

$\mathrm{UO}_{2}\left(\mathrm{NO}_{3}\right)_{2} \cdot 6 \mathrm{H}_{2} \mathrm{O}$ (depleted uranium, R. P. Normapur, 99\%) was purchased from Prolabo. 2-Sulfobenzoic acid cyclic anhydride, 3-sulfobenzoic acid sodium salt, and 4sulfobenzoic acid potassium salt were from Aldrich. $p$-Sulfonatocalix[4]arene hydrate was from Acros. $R, S$-Me - $_{6}$ clam (meso isomer of $7(R), 14(S)-5,5,7,12,12,14$-hexamethyl-1,4,8,11tetraazacyclotetradecane) was prepared as described in the literature. ${ }^{37}\left[\mathrm{Ni}(\mathrm{cyclam})\left(\mathrm{NO}_{3}\right)_{2}\right]$ and $\left[\mathrm{Cu}\left(R, S-\mathrm{Me}_{6}\right.\right.$ cyclam $\left.)\left(\mathrm{NO}_{3}\right)_{2}\right]$ were synthesized as described in previous work. ${ }^{25,28}$ Elemental analyses were performed by MEDAC Ltd. at Chobham, UK, or Service de Microanalyse du CNRS, Gif-sur-Yvette, France. For all syntheses performed under (solvo-)hydrothermal conditions (complexes 1-6), the mixtures in demineralized water/organic solvent were placed in $10 \mathrm{~mL}$ tightly closed glass vessels and heated at $140{ }^{\circ} \mathrm{C}$ under autogenous pressure, and the crystals were grown in the hot, pressurized solutions.

$[\mathrm{Ni}($ cyclam $)]\left[\mathrm{UO}_{2}(4-\mathrm{SB})_{2}\left(\mathrm{H}_{2} \mathrm{O}\right)_{2}\right] \cdot 2 \mathrm{CH}_{3} \mathrm{CN}(\mathbf{1})$. 4-Sulfobenzoic acid potassium salt $(24$ $\mathrm{mg}, 0.10 \mathrm{mmol}), \mathrm{UO}_{2}\left(\mathrm{NO}_{3}\right)_{2} \cdot 6 \mathrm{H}_{2} \mathrm{O}(35 \mathrm{mg}, 0.07 \mathrm{mmol})$, and [Ni(cyclam) $\left.\left(\mathrm{NO}_{3}\right)_{2}\right](20 \mathrm{mg}, 0.05$ $\mathrm{mmol})$ were dissolved in water $(0.4 \mathrm{~mL})$ and acetonitrile $(0.2 \mathrm{~mL})$. Orange crystals of complex 1 were obtained within two weeks (15 mg, $29 \%$ yield based on the acid). Anal. calcd for $\mathrm{C}_{28} \mathrm{H}_{42} \mathrm{~N}_{6} \mathrm{NiO}_{14} \mathrm{~S}_{2} \mathrm{U}+0.5 \mathrm{H}_{2} \mathrm{O}: \mathrm{C}, 31.83 ; \mathrm{H}, 4.10 ; \mathrm{N}, 7.95$. Found: C, 31.82; H, 3.80; N, 7.64\%.

[Ni(cyclam)][UO $\left.\mathrm{UO}_{2}(3-\mathrm{SB})_{2}\left(\mathrm{H}_{2} \mathrm{O}\right)_{2}\right]$ (2). 3-sulfobenzoic acid sodium salt (23 mg, 0.10 $\mathrm{mmol}), \mathrm{UO}_{2}\left(\mathrm{NO}_{3}\right)_{2} \cdot 6 \mathrm{H}_{2} \mathrm{O}(35 \mathrm{mg}, 0.07 \mathrm{mmol})$, and [Ni(cyclam) $\left.\left(\mathrm{NO}_{3}\right)_{2}\right](20 \mathrm{mg}, 0.05 \mathrm{mmol})$ were dissolved in water $(0.7 \mathrm{~mL})$ and acetonitrile $(0.2 \mathrm{~mL})$. Yellow-orange crystals of complex 2 were obtained within three days ( $20 \mathrm{mg}, 41 \%$ yield based on the acid). Anal. calcd for $\mathrm{C}_{24} \mathrm{H}_{36} \mathrm{~N}_{4} \mathrm{NiO}_{14} \mathrm{~S}_{2} \mathrm{U}$ : C, 29.86; H, 3.76; N, 5.80. Found: C, 29.86; H, 3.61; N, 5.86\%. 
$\left[\mathrm{UO}_{2}(2-\mathrm{SB})_{2} \mathrm{Ni}(\mathrm{cyclam})\right] \cdot \mathrm{H}_{2} \mathrm{O}(3)$. 2-Sulfobenzoic acid cyclic anhydride (19 mg, 0.10 $\mathrm{mmol}), \mathrm{UO}_{2}\left(\mathrm{NO}_{3}\right)_{2} \cdot 6 \mathrm{H}_{2} \mathrm{O}(35 \mathrm{mg}, 0.07 \mathrm{mmol})$, and $\left[\mathrm{Ni}(\right.$ cyclam $\left.)\left(\mathrm{NO}_{3}\right)_{2}\right](20 \mathrm{mg}, 0.05 \mathrm{mmol})$ were dissolved in water $(0.5 \mathrm{~mL})$. Orange crystals of complex 3 were obtained overnight (13 mg, $27 \%$ yield based on the acid). Anal. calcd for $\mathrm{C}_{24} \mathrm{H}_{34} \mathrm{~N}_{4} \mathrm{NiO}_{13} \mathrm{~S}_{2} \mathrm{U}: \mathrm{C}, 30.43 ; \mathrm{H}, 3.62$; N, 5.91. Found: C, 30.46; H, 3.47; N, 5.89\%.

$\left[\mathrm{UO}_{2}(2-\mathrm{SB})_{2} \mathrm{Cu}\left(R, S-\mathrm{Me}_{6} \text { cyclam }\right)\right]_{2} \cdot 2 \mathrm{H}_{2} \mathrm{O} \quad(4) \quad$ and $\quad\left[\left(\mathrm{UO}_{2}\right)_{2}(2-\mathrm{SB})_{2}\left(\mathrm{C}_{2} \mathrm{O}_{4}\right) \mathrm{Cu}(R, S-\right.$ $\mathrm{Me}_{6}$ cyclam)] (5). 2-Sulfobenzoic acid cyclic anhydride (19 mg, $\left.0.10 \mathrm{mmol}\right), \mathrm{UO}_{2}\left(\mathrm{NO}_{3}\right)_{2} \cdot 6 \mathrm{H}_{2} \mathrm{O}$ (35 mg, $0.07 \mathrm{mmol})$, and $\left[\mathrm{Cu}\left(R, S-\mathrm{Me}_{6}\right.\right.$ cyclam $\left.)\left(\mathrm{NO}_{3}\right)_{2}\right](24 \mathrm{mg}, 0.05 \mathrm{mmol})$ were dissolved in water $(0.5 \mathrm{~mL})$ and acetonitrile $(0.2 \mathrm{~mL})$. A mixture of purple crystals of 4 and orange crystals of 5 were obtained within four days $(32 \mathrm{mg})$.

$\left[\mathrm{PPh}_{4}\right]_{2}\left[\left(\mathrm{UO}_{2}\right)_{2}(2-\mathrm{SB})_{3}\left(\mathrm{H}_{2} \mathrm{O}\right)\right] \cdot \mathrm{H}_{2} \mathrm{O}$ (6). 2-Sulfobenzoic acid cyclic anhydride (19 mg, $0.10 \mathrm{mmol}), \mathrm{UO}_{2}\left(\mathrm{NO}_{3}\right)_{2} \cdot 6 \mathrm{H}_{2} \mathrm{O}(35 \mathrm{mg}, 0.07 \mathrm{mmol})$, and $\mathrm{PPh}_{4} \mathrm{Br}(42 \mathrm{mg}, 0.10 \mathrm{mmol})$ were dissolved in water $(0.7 \mathrm{~mL})$ and acetonitrile $(0.2 \mathrm{~mL})$. Yellow crystals of complex 6 were obtained within four days $(11 \mathrm{mg}, 18 \%$ yield based on the acid). Anal. calcd for $\mathrm{C}_{69} \mathrm{H}_{56} \mathrm{O}_{21} \mathrm{P}_{2} \mathrm{~S}_{3} \mathrm{U}_{2}: \mathrm{C}, 44.67 ; \mathrm{H}, 3.04$. Found: C, 44.62; H, $2.97 \%$.

$\left[\left\{\mathrm{Cu}\left(R, S-\mathrm{Me}_{6} \text { cyclam }\right)\right\}_{5}\left(\mathrm{H}_{3} \mathrm{C} 4 \mathrm{~S}\right)_{2}\right] \cdot 17 \mathrm{H}_{2} \mathrm{O}$ (7). p-Sulfonatocalix[4]arene hydrate (26 $\mathrm{mg}, \sim 0.03 \mathrm{mmol}), \mathrm{UO}_{2}\left(\mathrm{NO}_{3}\right)_{2} \cdot 6 \mathrm{H}_{2} \mathrm{O}(25 \mathrm{mg}, 0.05 \mathrm{mmol})$, and $\left[\mathrm{Cu}\left(R, S-\mathrm{Me}_{6} \mathrm{cyclam}\right)\left(\mathrm{NO}_{3}\right)_{2}\right](24$ $\mathrm{mg}, 0.05 \mathrm{mmol})$ were dissolved in water $(1.2 \mathrm{~mL})$ and DMF $(0.9 \mathrm{~mL})$. Purple crystals of complex 7 were obtained after slow evaporation of the solution at room temperature over a period of one week (14 mg, $40 \%$ yield based on $\mathrm{Cu}$ ). Anal. calcd for $\mathrm{C}_{136} \mathrm{H}_{252} \mathrm{Cu}_{5} \mathrm{~N}_{20} \mathrm{O}_{49} \mathrm{~S}_{8}$ : $\mathrm{C}$, 46.33; H, 7.20; N, 7.95. Found: C, 46.18; H, 7.18; N, 7.87\%.

$$
\left[\mathrm{PPh}_{4}\right]_{5}\left[\mathrm{UO}_{2}\left(\mathrm{H}_{4} \mathrm{C} 4 \mathrm{~S}\right)\left(\mathrm{H}_{2} \mathrm{O}\right)_{4}\right]\left[\mathrm{UO}_{2}\left(\mathrm{H}_{3} \mathrm{C} 4 \mathrm{~S}\right)\left(\mathrm{H}_{2} \mathrm{O}\right)_{4}\right] \cdot 14 \mathrm{H}_{2} \mathrm{O}
$$

and $\left[\mathrm{PPh}_{4}\right]_{3}\left[\mathrm{UO}_{2}\left(\mathrm{H}_{3} \mathrm{C} 4 \mathrm{~S}\right)\left(\mathrm{H}_{2} \mathrm{O}\right)_{3}\right] \cdot 9 \mathrm{H}_{2} \mathrm{O} \quad$ (9). $p$-Sulfonatocalix[4]arene hydrate $(26 \mathrm{mg}, \quad 0.03$ $\mathrm{mmol}), \mathrm{UO}_{2}\left(\mathrm{NO}_{3}\right)_{2} \cdot 6 \mathrm{H}_{2} \mathrm{O}(25 \mathrm{mg}, 0.05 \mathrm{mmol}), \mathrm{Gd}\left(\mathrm{NO}_{3}\right)_{3} \cdot 5 \mathrm{H}_{2} \mathrm{O}(22 \mathrm{mg}, 0.05 \mathrm{mmol})$, and $\mathrm{PPh}_{4} \mathrm{Br}(21 \mathrm{mg}, 0.05 \mathrm{mmol})$ were dissolved in water $(0.7 \mathrm{~mL})$ and acetonitrile $(0.2 \mathrm{~mL})$. A 
mixture of yellow crystals of $\mathbf{8}$ and yellow-orange crystals of $\mathbf{9}$ were obtained after slow evaporation of the solution at room temperature over a period of one week (15 mg). Crystals of 9 were largely predominant, as shown by elemental analysis results. Anal. calcd for $\mathrm{C}_{100} \mathrm{H}_{103} \mathrm{O}_{30} \mathrm{P}_{3} \mathrm{~S}_{4} \mathrm{U}(\mathbf{9})$ : C, 53.52; H, 4.63. Found: C, 53.62; H, $4.31 \%$.

$\left[\mathrm{PPh}_{4}\right]_{2}\left[\mathrm{UO}_{2}\left(\mathrm{H}_{4} \mathrm{C} 4 \mathrm{~S}\right)\left(\mathrm{H}_{2} \mathrm{O}\right)_{3}\right] \cdot 11 \mathrm{H}_{2} \mathrm{O}(\mathbf{1 0}) . p$-Sulfonatocalix[4]arene hydrate $(26 \mathrm{mg}$, $\sim 0.03 \mathrm{mmol}), \mathrm{UO}_{2}\left(\mathrm{NO}_{3}\right)_{2} \cdot 6 \mathrm{H}_{2} \mathrm{O}(25 \mathrm{mg}, 0.05 \mathrm{mmol})$, and $\mathrm{PPh}_{4} \mathrm{Br}(21 \mathrm{mg}, 0.05 \mathrm{mmol})$ were dissolved in water $(0.7 \mathrm{~mL})$ and acetonitrile $(0.2 \mathrm{~mL})$. Yellow crystals of complex $\mathbf{1 0}$ were obtained in low yield after slow evaporation of the solution at room temperature over a period of one week.

\section{Crystallography}

The data were collected at 100(2) K on a Nonius Kappa-CCD area detector diffractometer ${ }^{38}$ using graphite-monochromated Mo K $\alpha$ radiation $(\lambda=0.71073 \AA)$. The crystals were introduced into glass capillaries with a protective coating of Paratone-N oil (Hampton Research). The unit cell parameters were determined from ten frames, then refined on all data. The data (combinations of $\varphi$ - and $\omega$-scans with a minimum redundancy of at least 4 for $90 \%$ of the reflections) were processed with HKL2000. ${ }^{39}$ Absorption effects were corrected empirically with the program SCALEPACK. ${ }^{39}$ The structures were solved by intrinsic phasing with SHELXT, ${ }^{40}$ expanded by subsequent difference Fourier synthesis and refined by full-matrix least-squares on $F^{2}$ with SHELXL-2014. ${ }^{41}$ All non-hydrogen atoms were refined with anisotropic displacement parameters. The hydrogen atoms bound to oxygen and nitrogen atoms were retrieved from difference Fourier maps when possible (those of some water solvent molecules were neither found, nor introduced in complexes $\mathbf{3 , 8}$ and $\mathbf{1 0}$ ), and the carbon-bound hydrogen atoms were introduced at calculated positions. All hydrogen atoms were treated as riding atoms with an isotropic displacement parameter equal to 1.2 times that of the parent atom 
(1.5 for $\mathrm{CH}_{3}$, with optimized geometry). In complex $\mathbf{3}$, the free water molecule is disordered over two sites which have been refined with occupancy parameters constrained to sum to unity and restraints on displacement parameters. Other water solvent molecules, in excess of those present in the formula, are present in complex $\mathbf{8}$, which could not be modeled properly; their contribution to the structure factors was taken into account with the PLATON/SQUEEZE software. ${ }^{42}$ Crystal data and structure refinement parameters are given in Table 1. The molecular plots were drawn with ORTEP- $3,{ }^{43}$ and the polyhedral representations with VESTA (Version 3.4.4). ${ }^{44}$ The topological analyses were conducted with TOPOS (Version 4.0). ${ }^{45}$

\section{Luminescence Measurements}

Emission spectra were recorded on solid samples using a Horiba-Jobin-Yvon IBH FL-322 Fluorolog 3 spectrometer equipped with a $450 \mathrm{~W}$ xenon arc lamp, double-grating excitation and emission monochromator $(2.1 \mathrm{~nm} / \mathrm{mm}$ of dispersion; 1200 grooves $/ \mathrm{mm})$ and a TBX-04 single photon-counting detector. The powdered compounds were put into a quartz tube and pressed to the wall of the tube, and the measurements were performed using the right angle mode. An excitation wavelength of $420 \mathrm{~nm}$, a commonly used point although only part of a broad manifold, ${ }^{46}$ was used in all cases and the emission was monitored between 450 and $650 \mathrm{~nm}$. The quantum yield measurements were performed by using a Hamamatsu Quantaurus C11347 absolute photoluminescence quantum yield spectrometer and exciting the sample between 300 and $400 \mathrm{~nm}$. 
Table 1 Crystal data and structure refinement details

\begin{tabular}{|c|c|c|c|c|c|}
\hline & 1 & 2 & 3 & 4 & 5 \\
\hline Chemical formula & $\mathrm{C}_{28} \mathrm{H}_{42} \mathrm{~N}_{6} \mathrm{NiO}_{14} \mathrm{~S}_{2} \mathrm{U}$ & $\mathrm{C}_{24} \mathrm{H}_{36} \mathrm{~N}_{4} \mathrm{NiO}_{14} \mathrm{~S}_{2} \mathrm{U}$ & $\mathrm{C}_{24} \mathrm{H}_{34} \mathrm{~N}_{4} \mathrm{NiO}_{13} \mathrm{~S}_{2} \mathrm{U}$ & $\mathrm{C}_{60} \mathrm{H}_{92} \mathrm{Cu}_{2} \mathrm{~N}_{8} \mathrm{O}_{26} \mathrm{~S}_{4} \mathrm{U}_{2}$ & $\mathrm{C}_{32} \mathrm{H}_{44} \mathrm{CuN}_{4} \mathrm{O}_{18} \mathrm{~S}_{2} \mathrm{U}_{2}$ \\
\hline$M / \mathrm{g} \mathrm{mol}^{-1}$ & 1047.53 & 965.43 & 947.41 & 2072.79 & 1376.43 \\
\hline Crystal system & Monoclinic & Monoclinic & Monoclinic & Triclinic & Monoclinic \\
\hline Space group & $P 2_{1} / c$ & $P 2_{1} / c$ & $P 2_{1} / n$ & $P_{\overline{1}}$ & $P 2_{1} / c$ \\
\hline a/§ & $8.4686(3)$ & $10.6905(5)$ & $9.8537(2)$ & $11.6903(6)$ & $11.3508(8)$ \\
\hline$b / \AA$ & $9.9123(4)$ & $14.6528(6)$ & $15.8019(6)$ & $11.6969(5)$ & $13.7624(5)$ \\
\hline$c / \AA$ & $21.7475(8)$ & $9.9092(3)$ & $20.3332(7)$ & $14.5245(8)$ & $14.1862(9)$ \\
\hline$\alpha l^{\circ}$ & 90 & 90 & 90 & $94.145(3)$ & 90 \\
\hline$\beta /^{\circ}$ & $93.972(2)$ & $91.272(3)$ & $99.894(2)$ & $97.373(3)$ & $103.615(3)$ \\
\hline$y^{\circ}$ & 90 & 90 & 90 & $107.703(3)$ & 90 \\
\hline$V / \AA^{3}$ & $1821.17(12)$ & $1551.85(11)$ & $3118.94(17)$ & $1863.32(17)$ & $2153.8(2)$ \\
\hline Z & 2 & 2 & 4 & 1 & 2 \\
\hline Reflections collected & 48315 & 41974 & 155921 & 105270 & 101431 \\
\hline Independent reflections & 3452 & 2937 & 5902 & 7080 & 4088 \\
\hline Observed reflections $[I>2 \sigma(I)]$ & 2865 & 2522 & 5292 & 6532 & 3300 \\
\hline$R_{\text {int }}$ & 0.025 & 0.024 & 0.021 & 0.059 & 0.029 \\
\hline Parameters refined & 239 & 211 & 416 & 466 & 271 \\
\hline$R_{1}$ & 0.027 & 0.020 & 0.025 & 0.026 & 0.026 \\
\hline$w R_{2}$ & 0.072 & 0.053 & 0.069 & 0.057 & 0.068 \\
\hline$S$ & 1.075 & 1.038 & 1.094 & 1.052 & 1.090 \\
\hline$\Delta \rho_{\min } / \mathrm{e} \AA^{-3}$ & -1.35 & -1.07 & -0.97 & -1.38 & -1.91 \\
\hline$\Delta \rho_{\max } / \mathrm{e} \AA^{-3}$ & 1.29 & 0.60 & 1.39 & 2.12 & 1.42 \\
\hline
\end{tabular}

\begin{tabular}{|c|c|c|c|c|c|}
\hline & 6 & 7 & 8 & 9 & 10 \\
\hline Chemical formula & $\mathrm{C}_{69} \mathrm{H}_{56} \mathrm{O}_{21} \mathrm{P}_{2} \mathrm{~S}_{3} \mathrm{U}_{2}$ & $\mathrm{C}_{136} \mathrm{H}_{252} \mathrm{Cu}_{5} \mathrm{~N}_{20} \mathrm{O}_{49} \mathrm{~S}_{8}$ & $\mathrm{C}_{176} \mathrm{H}_{183} \mathrm{O}_{58} \mathrm{P}_{5} \mathrm{~S}_{8} \mathrm{U}_{2}$ & $\mathrm{C}_{100} \mathrm{H}_{103} \mathrm{O}_{30} \mathrm{P}_{3} \mathrm{~S}_{4} \mathrm{U}$ & $\mathrm{C}_{76} \mathrm{H}_{88} \mathrm{O}_{32} \mathrm{P}_{2} \mathrm{~S}_{4} \mathrm{U}$ \\
\hline$M / \mathrm{g} \mathrm{mol}^{-1}$ & 1855.31 & 3525.74 & 4113.60 & 2244.00 & 1941.67 \\
\hline Crystal system & Triclinic & Triclinic & Triclinic & Monoclinic & Triclinic \\
\hline Space group & $P \overline{1}$ & $P \overline{1}$ & $P \overline{1}$ & $P 2_{1} / n$ & $P \overline{1}$ \\
\hline$a / \AA$ & $19.5550(8)$ & $14.9382(9)$ & $16.8351(4)$ & $18.3929(3)$ & $13.7110(9)$ \\
\hline$b / \AA$ & $19.7854(7)$ & $16.2333(11)$ & $23.7794(12)$ & $25.4078(6)$ & $13.9471(6)$ \\
\hline$c / \AA ̊$ & $22.8580(8)$ & $20.2169(14)$ & $23.8357(11)$ & $20.6753(5)$ & $22.3786(16)$ \\
\hline$\alpha /^{\circ}$ & $67.635(3)$ & $74.324(3)$ & $70.701(2)$ & 90 & $105.108(4)$ \\
\hline$\beta /^{\circ}$ & $65.121(2)$ & $68.424(3)$ & $79.095(3)$ & $93.6933(14)$ & $100.002(3)$ \\
\hline$y^{\circ}$ & $60.589(2)$ & $64.208(3)$ & $89.039(3)$ & 90 & $96.077(4)$ \\
\hline$V / \AA^{3}$ & $6817.8(5)$ & $4069.1(5)$ & $8832.5(7)$ & $9642.0(4)$ & $4017.0(4)$ \\
\hline$Z$ & 4 & 1 & 2 & 4 & 2 \\
\hline Reflections collected & 345019 & 195268 & 447630 & 329560 & 199629 \\
\hline Independent reflections & 25827 & 15436 & 33494 & 18287 & 15250 \\
\hline Observed reflections $[I>2 \sigma(I)]$ & 18227 & 11140 & 23423 & 15381 & 11972 \\
\hline$R_{\text {int }}$ & 0.061 & 0.045 & 0.063 & 0.027 & 0.050 \\
\hline Parameters refined & 1748 & 1003 & 2242 & 1243 & 1042 \\
\hline$R_{1}$ & 0.033 & 0.039 & 0.051 & 0.039 & 0.039 \\
\hline$w R_{2}$ & 0.064 & 0.097 & 0.116 & 0.096 & 0.091 \\
\hline$S$ & 0.905 & 0.999 & 1.043 & 1.071 & 0.970 \\
\hline$\Delta \rho_{\min } / \mathrm{e} \AA^{-3}$ & -1.24 & -0.54 & -1.71 & -1.18 & -1.07 \\
\hline$\Delta \rho_{\max } / \mathrm{e} \AA^{-3}$ & 1.54 & 0.80 & 1.08 & 2.27 & 1.58 \\
\hline
\end{tabular}

\section{Results and discussion}

\section{Synthesis}

Complexes 1, 2 and 4-6 were synthesized under solvo-hydrothermal conditions in water/acetonitrile and $\mathbf{3}$ under purely hydrothermal conditions, at a temperature of $140{ }^{\circ} \mathrm{C}$. The crystals obtained were deposited directly from the pressurised and heated reaction mixtures and not as a result of subsequent cooling. The uranium/ligand ratio was 7:10 in all cases, so as to 
favour the formation of an anionic species, but the expected ratio of 2:3 was retained in complex 6 only. Oxalate ligands formed in situ, a frequent occurrence in (solvo-)hydrothermal syntheses, ${ }^{47-49}$ were also present as coligands in complex 5. It is interesting to note that the only case in which oxalate is present here was that in which $\left[\mathrm{Cu}\left(R, S-\mathrm{Me}_{6} \mathrm{cyclam}\right)\right]^{2+}$ cations were present, as observed in a previous series of complexes, ${ }^{28}$ which is possibly indicative of its formation through oxidative decomposition of the macrocycle.

The advantages of the use of (solvo-)hydrothermal methods for synthesis of complexes of the type presently studied may arise from a variety of factors, although it is not often obvious what factors may be most important. Thus, the formation, as presently, of crystals under the hot, pressurized conditions may indicate that their dissolution is an exothermic process, which is however unlikely since the crystals remain insoluble at room temperature, or, more plausibly, that materials which are extremely insoluble at room temperature and deposit then as amorphous solids are sufficiently soluble at elevated temperatures for the kinetics of their deposition to be slow and compatible with crystal formation. That the synthesis of anionic uranyl ion complexes requiring a heterocation for their crystallization can be achieved under (solvo-)hydrothermal conditions by simple addition of the heterocation without the need to add a base to achieve deprotonation of the conjugate acid of the complexing, anionic ligand in quantities beyond that necessary for formation of a simple neutral complex ${ }^{34}$ may reflect a complicated interaction of acidity and solubility variations with temperature (and pressure). The lack of any base addition is considered important in limiting the formation of hydrolytic polymers of uranyl ion, although a $\mathrm{pH}$ increase in some aqueous solvent mixtures such as water/DMF or water/ $\mathrm{CH}_{3} \mathrm{CN}$ is unavoidable due to hydrolytic cleavage of the organic solvent under the relatively extreme reaction conditions, cleavage probably accelerated by uranyl ion and/or heterocation catalysis. ${ }^{24,26,27}$ In the present instances, such reactions may have assisted ligand deprotonation to the degree desired, although unlike many other cases, ${ }^{24,26,27}$ cosolvent 
hydrolysis products were not present in the isolated solids and thus did not aid in crystallization in this way. Solvothermal synthesis ${ }^{50}$ has of course been a highly successful pathway to an enormous variety of crystalline complexes, but it is worth noting that the very numerous instances where it does not provide a crystalline product are usually not reported and that it is solubility and not necessarily solution stability that determines the nature of any isolated species. Given as well that so little is known in general of the solution equilibria existing in (solvo-)hydrothermal media, interpretation of the structural results demands considerable caution. In the present instances, given the expectation that sulfonate donors should be poor ligands in aqueous solution, it can only be said that what is seen in the solid state only indicates possible modes of coordination in solution and that the interactions seen of sulfonate entities in the crystals may be more an effect of solubility than of preferred coordination modes.

In contrast to the complexes with sulfobenzoate ligands, those with $p$ sulfonatocalix[4]arene were synthesized at room temperature, by slow evaporation of solutions in water/DMF (7) or water/acetonitrile (8-10). Complexes 8 and 9 were obtained together from a solution containing also gadolinium(III) cations, intended to generate a heterometallic complex, but which are absent from the final species (although such uranyl-lanthanide complexes with this ligand are known ${ }^{9}$ ). The three uranyl ion complexes 8-10 contain $\mathrm{PPh}_{4}{ }^{+}$ counterions, but an attempt to include $\left[\mathrm{Cu}\left(R, S-\mathrm{Me}_{6} \text { cyclam }\right)\right]^{2+}$ cations resulted in the copperonly complex 7 .

\section{Crystal structures}

Sulfobenzoate complexes. Assuming coordination through both carboxylate and sulfonate units, the ligand 4-sulfobenzoate $\left(4-\mathrm{SB}^{2-}\right)$ would seem well suited to the formation of one- or two-dimensional (1D or 2D) coordination polymers with uranyl ion. Crystallized in the

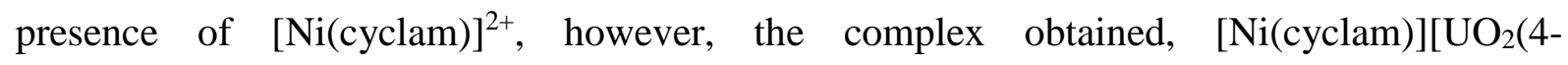


$\left.\mathrm{SB})_{2}\left(\mathrm{H}_{2} \mathrm{O}\right)_{2}\right] \cdot 2 \mathrm{CH}_{3} \mathrm{CN}(\mathbf{1})$, can be considered to contain a centrosymmetric mononuclear uranyl complex unit in which just the carboxylate groups are coordinated in a $\kappa^{2}-O, O^{\prime}$ fashion, two trans-located water molecules completing the hexagonal bipyramidal coordination sphere of the unique uranium ion (Fig. 1). The $\mathrm{U}-\mathrm{O}$ bond lengths are unexceptional [U-O(oxido)

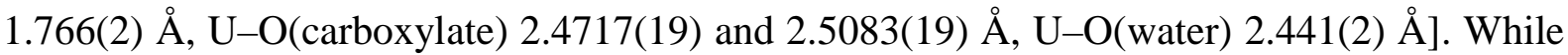
clearly not coordinated to uranium, the sulfonate groups of two uranium complexes lie, symmetrically, close to the axial positions of the centrosymmetric $[\mathrm{Ni}(\mathrm{cyclam})]^{2+}$ units, although the shortest $\mathrm{Ni}-\mathrm{O}$ distance of 2.987(2) $\AA$ with atom O4 is long compared to those seen
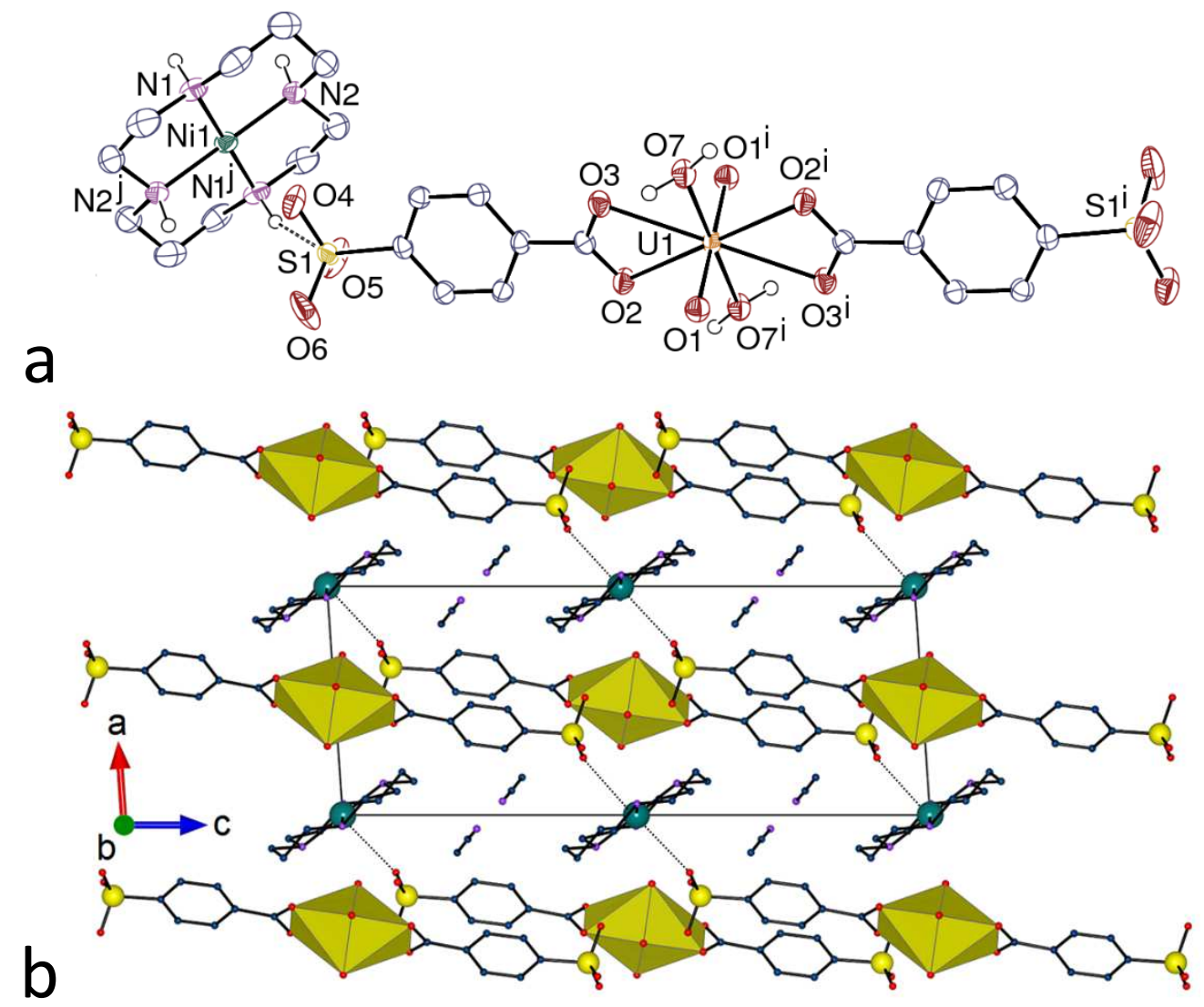

Fig. 1 (a) View of compound 1. Displacement ellipsoids are drawn at the 50\% probability level. Solvent molecules and carbon-bound hydrogen atoms are omitted, and the hydrogen bond is shown as a dashed line. Symmetry codes: $\mathrm{i}=1-x, 1-y, 1-z ; \mathrm{j}=-x, 1-y, 2-z$. (b) View of the packing with uranium coordination polyhedra colored yellow, nickel(II) ions shown as green spheres, and hydrogen atoms omitted. The $\mathrm{Ni} \cdots$ sulfonate interactions are shown as dashed lines. 




Fig. 2 Hirshfeld surface of the $[\mathrm{Ni}(\text { cyclam })]^{2+}$ counterion in complex 1 mapped with $d_{\text {norm, }}$, showing the weak

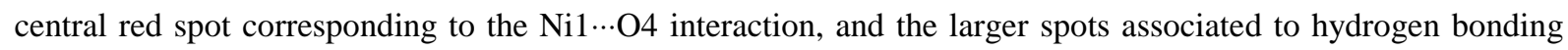
interactions. Red spots correspond to distances shorter than the sum of van der Waals radii. The hydrogen bond is shown as a dashed line.

in most $\mathrm{NiN}_{4} \mathrm{O}_{2}$ species considered to involve 6-coordinate $\mathrm{Ni}^{\mathrm{II}}$, where carboxylate- $O$ donors, for example, ${ }^{51}$ give $\mathrm{Ni}-\mathrm{O} \sim 2.1 \AA$. In fact, analysis of the Hirshfeld surface $(\mathrm{HS})^{52}$ of the cation, calculated using CrystalExplorer (Version 3.1) ${ }^{53}$ and shown in Fig. 2, indicates that the surface is more affected by hydrogen bonding interactions between $\mathrm{N} 1$ and $\mathrm{O} 5$ or $\mathrm{N} 2$ and $\mathrm{O} 6$ [N $\cdots \mathrm{O}$ 2.924(3) and 2.945(4) $\AA, \mathrm{N}-\mathrm{H} \cdots \mathrm{O} 159^{\circ}$ for both]. These are not the only hydrogen bond acceptor interactions of the sulfonate group, as the HS for the anionic uranyl complex shows O4, O5 and O6 to be also involved in hydrogen bonds to the uranyl-coordinated water molecules $\left[\mathrm{O} \cdots \mathrm{O} 2.934(3)-3.232(4) \AA\right.$, O-H $\left.\cdots \mathrm{O} 132-159^{\circ}\right]$, the combination of all resulting in three-dimensional (3D) linking of the lattice components. Thus, the interaction $\mathrm{N} 1-\mathrm{H} \cdots \mathrm{O} 5$, along with the weak coordination interaction $\mathrm{Ni} \cdots \mathrm{O} 4$, defines stepped chains of alternating cations and anions directed along [10י] and lying side by side in sheets parallel to (010). Within these sheets, the chains are cross linked by the $\mathrm{N} 2 \cdots \mathrm{O} 6$ interactions, while the linear $\mathrm{U}\left(\mathrm{H}_{2} \mathrm{O}\right)_{2}$ units are linked along the $b$ axis by the hydrogen bonding interactions with sulfonate groups of neighbouring sheets, the overall packing being quite compact, with a Kitaigorodski packing index (KPI) of 0.71 (estimation with PLATON ${ }^{54}$ ). Examination of short contacts with PLATON 
gives no evidence of $\pi$-stacking or $\mathrm{CH} \cdots \pi$ interactions. Hydrogen bonding is thus the most obvious influence upon the form of the lattice array and while axial coordination of the $[\mathrm{Ni}(\mathrm{cyclam})]^{2+}$ units may have some effect, it appears that it is at most barely competitive with $\mathrm{N}-\mathrm{H} \cdots \mathrm{O}$ bonding and thus must involve an energy $\sim 15-20 \mathrm{~kJ} \mathrm{~mol}^{-1} .55$

Given that $3-\mathrm{SB}^{2-}$ is another species for which simple $\kappa^{1}-O(S) ; \kappa^{1}-O(C)$ chelation cannot occur, it is unsurprising to find that the lattice in $[\mathrm{Ni}($ cyclam $)]\left[\mathrm{UO}_{2}(3-\mathrm{SB})_{2}\left(\mathrm{H}_{2} \mathrm{O}\right)_{2}\right](2)$ also contains centrosymmetric mononuclear uranyl complex units with an essentially identical uranium coordination sphere involving two $\mathrm{K}^{2}-O, O^{\prime}$ carboxylate chelates and two trans-located water molecules (Fig. 3). The U-O bond lengths are comparable to those in $\mathbf{1}$, although carboxylate chelation is slightly more asymmetric [U-O(oxido) 1.7691(17) $\AA$, U$\mathrm{O}$ (carboxylate) 2.4251(16) and 2.5075(18) $\AA$, U-O(water) 2.4863(17) $\AA$ ]. These mononuclear complexes are linked into a 3D network through interactions with the $[\mathrm{Ni}(\mathrm{cyclam})]^{2+}$ cations which appear to be exclusively of a hydrogen bonding nature. Thus, the HS of the cation shows no evidence for axial coordination and indicates only $\mathrm{NH} \cdots \mathrm{O}$ (sulfonate) bonding involving $\mathrm{N} 1$ and $\mathrm{N} 2$ as donors and $\mathrm{O} 4$ and $\mathrm{O} 5$ (in different complex units) as acceptors [N‥O 2.889(3) and 2.860(3) $\AA$, $\mathrm{N}-\mathrm{H} \cdots \mathrm{O} 170$ and $164^{\circ}$ ]. This is augmented by $\mathrm{OH} \cdots \mathrm{O}$ bonding involving

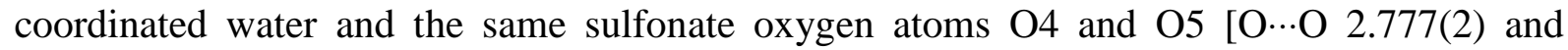
2.723(2) $\AA, \mathrm{O}-\mathrm{H} \cdots \mathrm{O} 168$ and $158^{\circ}$ ], an effect which perhaps draws the sulfonate oxygen atoms even further from the $\mathrm{Ni}^{\mathrm{II}}$ axial coordination positions. The generally shorter hydrogen bond distances in $\mathbf{2}$ in comparison to those of $\mathbf{1}$ may explain why hydrogen bonding appears to completely dominate coordinate bonding in this species. Analysis of short contacts indicates the possible presence of a weak parallel-displaced $\pi$-stacking interaction [centroid $\cdots$ centroid distance 4.4622(15) $\AA$, slippage $2.75 \AA$ ] , which however the HS shows to be no stronger than 



Fig. 3 (a) View of compound 2. Displacement ellipsoids are drawn at the 50\% probability level. Carbon-bound hydrogen atoms are omitted, and the hydrogen bond is shown as a dashed line. Symmetry codes: $\mathrm{i}=1-x, 2-y$, $-z ; \mathrm{j}=2-x, 1-y, 1-z .(\mathrm{b}, \mathrm{c})$ Two views of the packing with uranium coordination polyhedra colored yellow, nickel(II) ions shown as green spheres, and hydrogen atoms omitted. 
dispersion. The packing displays alternate layers of anions and cations parallel to (100); the former are held by water-sulfonate hydrogen bonding between complex units forming a herringbone patttern, and they are associated to one another along the $a$ axis through cationmediated hydrogen bonding, thus forming a 3D network. With a KPI of 0.72 , the packing contains no solvent-accessible space.

As expected from related work, ${ }^{14,15,18-21}$ modification of an aromatic sulfonate by introduction of a strong coordinating group adjacent to the sulfonate favours its coordination to uranyl ion and $2-\mathrm{SB}^{2-}$ does indeed act as a chelate through both substituents in the complex $\left[\mathrm{UO}_{2}(2-\mathrm{SB})_{2} \mathrm{Ni}(\right.$ cyclam $\left.)\right] \cdot \mathrm{H}_{2} \mathrm{O}(3)$, represented in Fig. 4. The unique uranyl cation is chelated by two ligands in the $\kappa^{1}-O(S) ; \kappa^{1}-O(C)$ mode, and is bound to one additional carboxylate oxygen atom, thus having a pentagonal bipyramidal geometry [U-O(oxido) 1.751(3) and 1.766(3) A, U-O(carboxylate) 2.338(3)-2.383(3) A, U-O(sulfonate) 2.407(3) and 2.413(3) $\AA$ ]. The bond lengths with sulfonate oxygen atoms in particular are in agreement with the average value of 2.40(4) $\AA$ for the 66 cases reported in the Cambridge Structural Database (CSD, Version 5.39) ${ }^{56}$ Centrosymmetric dinuclear uranyl-containing subunits are formed, which are identical to those found earlier in $\left[4,4^{\prime}-\mathrm{bipyH}_{2}\right]\left[\mathrm{UO}_{2}(2-\mathrm{SB})_{2}\right] .{ }^{18}$ The $[\mathrm{Ni}(\text { cyclam })]^{2+}$ cation is axially bound to one carboxylate and one sulfonate oxygen atoms, with bond lengths of 2.113(3) and 2.185(3) $\AA$, respectively, and the $\mathrm{Ni}^{\mathrm{II}}$ cation is thus in a slightly axially elongated octahedral environment (note that the difference between $\mathrm{Ni}-\mathrm{O}$ (sulfonate) and $\mathrm{Ni}-\mathrm{O}$ (carboxylate) bond lengths is small, showing that the long $\mathrm{Ni}-\mathrm{O}$ separation in $\mathbf{1}$ cannot simply be attributed to the weakness of sulfonate oxygen atoms as donors). Bonding of $\mathrm{Ni}^{\mathrm{iI}}$ to sulfonate is associated with

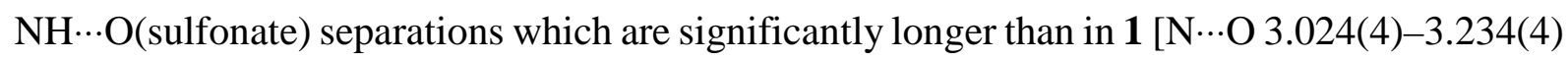
$\left.\AA, \mathrm{N}-\mathrm{H} \cdots \mathrm{O} 146-163^{\circ}\right]$ and this inversion of separations is reflected in the perturbations of the HS for the asymmetric unit of the structure, indicating that here coordinate bonding plays a far more important role in cation-anion association than does hydrogen bonding. In contrast to $\mathbf{1}$ 



Fig. 4 (a) View of compound 3. Displacement ellipsoids are drawn at the $50 \%$ probability level. The solvent molecule and carbon-bound hydrogen atoms are omitted, and the hydrogen bonds are shown as dashed lines. Symmetry codes: $\mathrm{i}=1-x, 2-y, 1-z ; \mathrm{j}=x-1 / 2,3 / 2-y, z-1 / 2 ; \mathrm{k}=x+1 / 2,3 / 2-y, z+1 / 2$. (b) View of the $2 \mathrm{D}$ network with uranium coordination polyhedra colored yellow and those of nickel(II) green, and hydrogen atoms omitted. (c) Simplified view of the network in the same orientation as in (b); yellow, uranium nodes; green, nickel links; blue, sulfobenzoate nodes and links.

and 2, other $\mathrm{NH} \cdots \mathrm{O}$ hydrogen bonds involve carboxylate oxygen atoms. Concerning the 2-SB ${ }^{2-}$ ligands, one of them is bound to one uranium and one nickel atoms, while the other connects two uranium and one nickel centres. A 2D coordination polymer is thus formed, parallel to 
(101), in which the dinuclear uranyl-containing subunits are linked through $[\mathrm{Ni}(\mathrm{cyclam})]^{2+}$ cations. The uranium atoms and one $2-\mathrm{SB}^{2-}$ ligand are nodes, whereas nickel atoms and the other 2-SB ${ }^{2-}$ ligand are simple links in the network, which has the $\left\{4.8^{2}\right\}$ point (Schläfli) symbol and the common fes topological type. Analysis of short contacts indicates the possible presence of a weak parallel-displaced $\pi$-stacking interaction [centroid $\cdots$ centroid distance $4.461(3) \AA$, dihedral angle $16.5(2)^{\circ}$ ], as well as two possible $\mathrm{CH} \cdots \pi$ interactions involving hydrogen atoms

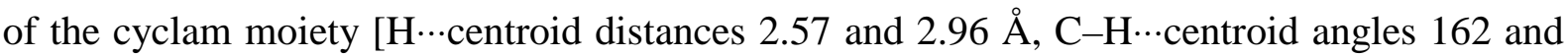
$113^{\circ}$ ]. The KPI, with disordered solvent excluded, is 0.67 .

The complex $\left[\mathrm{UO}_{2}(2-\mathrm{SB})_{2} \mathrm{Cu}\left(R, S-\mathrm{Me}_{6} \text { cyclam }\right)\right]_{2} \cdot 2 \mathrm{H}_{2} \mathrm{O}(4)$ has the same stoichiometry as 3, with $\left[\mathrm{Cu}\left(R, S-\mathrm{Me}_{6} \text { cyclam }\right)\right]^{2+}$ replacing $[\mathrm{Ni}(\text { cyclam })]^{2+}$, and the same centrosymmetric dinuclear uranyl-containing anion is present in the lattice (Fig. 5) [U-O(oxido) 1.769(3) and

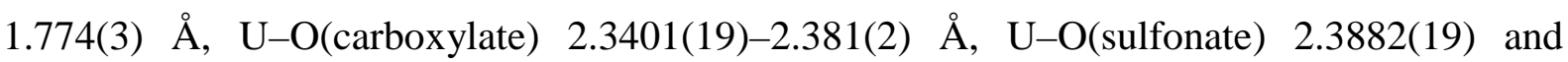
2.4193(19) ̊] . In this case, however, the complex can be regarded as a molecular species within the lattice, as the $\mathrm{Cu}^{\mathrm{II}}$ centre is axially bound to just one otherwise uncoordinated carboxylate oxygen atom [Cu1-O4 2.343(2) $\mathrm{A}$ ], with a square pyramidal environment geometry, and so does not adopt the 6-coordination seen for $\mathrm{Ni}^{\mathrm{II}}$ in $\mathbf{3}$, which formally links cations and anions into a 2D polymeric structure. Nonetheless, the molecular units in 4 are linked into a 1D hydrogen-bonded polymer running parallel to [010] through bonding of NH to sulfonate groups, either direct or mediated by the water molecule $\left[\mathrm{N} 4 \cdots \mathrm{O} 11^{\mathrm{j}} 3.045(4) \AA\right.$, $\mathrm{N} 4-\mathrm{H} \cdots \mathrm{O} 11^{\mathrm{j}} 172^{\circ}$

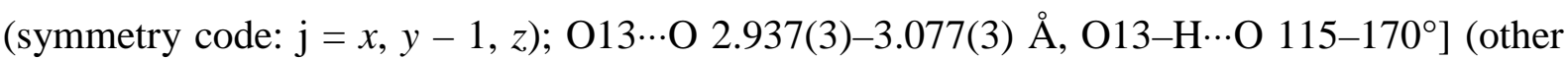
$\mathrm{NH} \cdots \mathrm{O}$ hydrogen bonds are intramolecular and involve either a carboxylate or a sulfonate group). All these interactions are apparent on the HS, which also provides evidence for a 

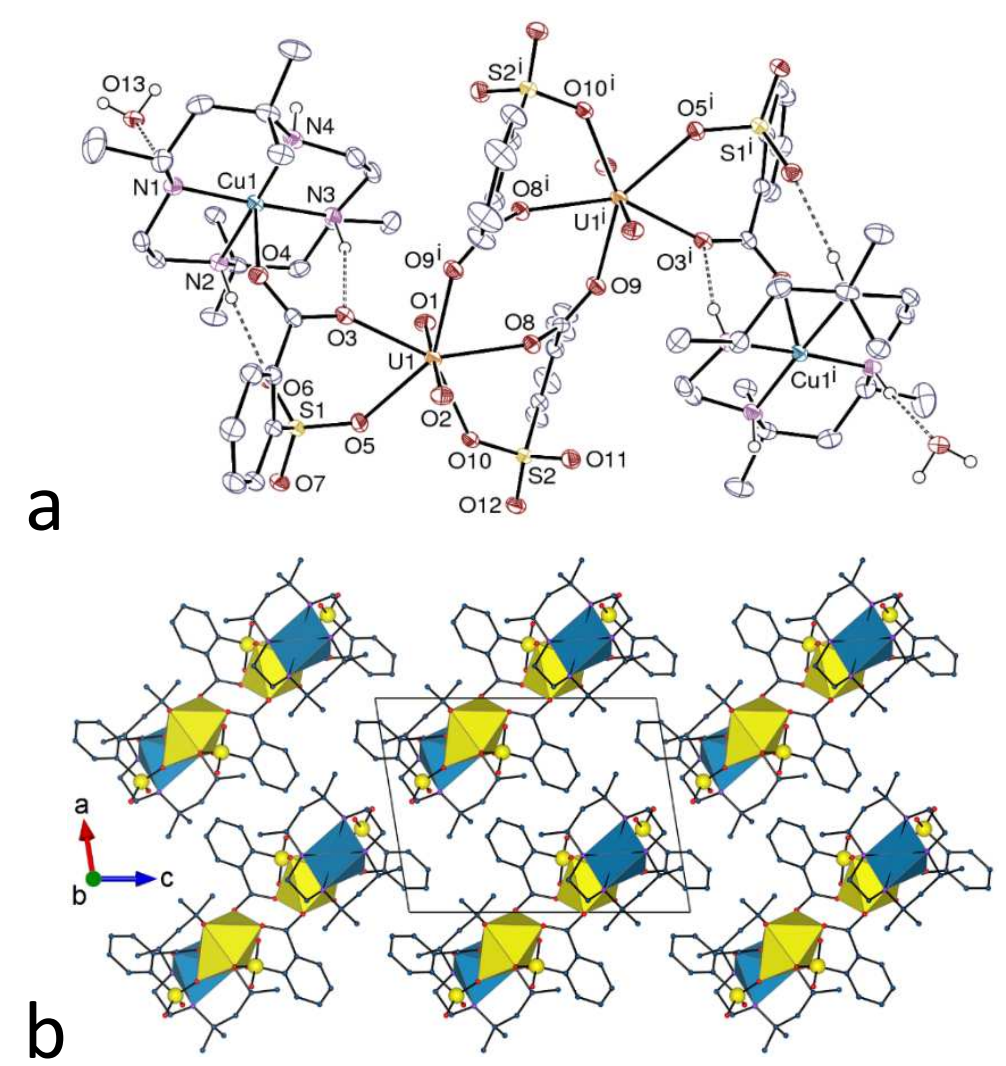

Fig. 5 (a) View of compound 4. Displacement ellipsoids are drawn at the $40 \%$ probability level. Carbon-bound hydrogen atoms are omitted, and the hydrogen bonds are shown as dashed lines. Symmetry code: $\mathrm{i}=2-x, 2-y$, $1-z$. (b) View of the packing with uranium coordination polyhedra colored yellow, and those of copper(II) blue. Solvent molecules and hydrogen atoms are omitted.

number of aliphatic- $\mathrm{CH} \cdots \mathrm{O}$ interactions ${ }^{57,58}$ involving the macrocyclic ligand and carboxylate,

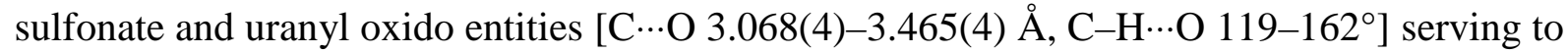
define the $3 \mathrm{D}$ form of the complete lattice. The fact that hydrogen bonding interactions of sulfonate around the second axial site of the $\mathrm{Cu}^{\mathrm{II}}$ macrocycle do not induce significant interaction with the metal ion indicates that the $\mathrm{Cu} \cdots \mathrm{O}$ (sulfonate) interaction energy in this case must be significantly less than that of an $\mathrm{NH} \cdots \mathrm{O}$ hydrogen bond, a result in conformity with the expectation that the preferred coordination number of $\mathrm{Cu}^{\mathrm{II}}$ is $5 .{ }^{59}$ No really significant $\pi$ stacking interaction is present in the lattice, the two only possible ones corresponding to 
centroid $\cdots$ centroid distances of 4.608(2) and 4.625(2) $\AA$. The ribbon-like chains are further

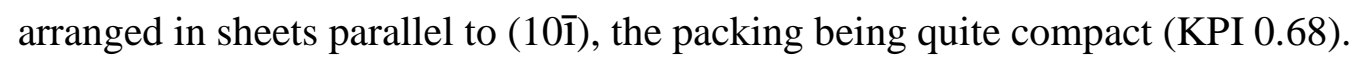

Complex $\left[\left(\mathrm{UO}_{2}\right)_{2}(2-\mathrm{SB})_{2}\left(\mathrm{C}_{2} \mathrm{O}_{4}\right) \mathrm{Cu}\left(R, S-\mathrm{Me}_{6}\right.\right.$ cyclam $\left.)\right]$ (5), obtained from the same reaction mixture which produced complex $\mathbf{4}$, again contains centrosymmetric dinuclear uranyl subunits with $2-\mathrm{SB}^{2-}$ ligands as bridging chelates but centrosymmetric oxalate anions replace the other $2-\mathrm{SB}^{2-}$ chelates seen in $\mathbf{3}$ and $\mathbf{4}$ and, in a bis(bidentate) bridging role, serve to link the dinuclear units into a linear polymer parallel to the $a$ axis, as shown in Fig. 6 [U-O(oxido) 1.760(3) $\AA$ (twice), U-O(carboxylate) 2.311(3)-2.434(3) $\AA$, U-O(sulfonate) 2.374(2) $\AA$ ]. These polymer strands lie in sheets parallel to (010) and are cross-linked by interactions between sulfonate groups and $\left[\mathrm{Cu}\left(R, S-\mathrm{Me}_{6} \mathrm{cyclam}\right)\right]^{2+}$ units. Here, the interactions occur symmetrically on both faces of the centrosymmetric macrocycle complex, so the sheets can be considered as 2D polymeric structures but the interactions are not simply consistent with $\mathrm{Cu}^{\mathrm{II}}$ in this case adopting 6-coordination. Perturbations of the HS of the cation (Fig. 7) actually provide evidence for a weak $\mathrm{Cu} \cdots \mathrm{O}$ (sulfonate) interaction, with a long $\mathrm{Cu} \cdots \mathrm{O} 6$ separation of $2.767(3) \AA$, along with two stronger interactions involving $\mathrm{NH} \cdots \mathrm{O}$ hydrogen bonds $\left[\mathrm{N} 1 \cdots \mathrm{O}^{\mathrm{k}} 2.847(4) \AA\right.$, N1$\mathrm{H} \cdots \mathrm{O}^{\mathrm{k}}{ }^{\mathrm{k}} 135^{\circ} ; \mathrm{N} 2 \cdots \mathrm{O} 72.966(4) \AA \stackrel{\mathrm{A}}{ }, \mathrm{N} 2-\mathrm{H} \cdots \mathrm{O} 7160^{\circ}$; symmetry code: $\left.\mathrm{k}=-x, 1-y,-z\right]$. Thus, as in $\mathbf{1}$, the coordinate bond can be seen as one induced by the adjacent hydrogen bonds. If the copper(II) axial bonding is considered significant, the 2D network formed has the point symbol $\left\{4.8^{2}\right\}$ and the fes topological type, as that in complex 3. No $\pi$-stacking interaction is present, and only two $\mathrm{CH} \cdots \mathrm{O}$ and one $\mathrm{CH} \cdots \pi$ interactions are possibly significant. The KPI of 0.66 indicates no solvent-accessible space. 


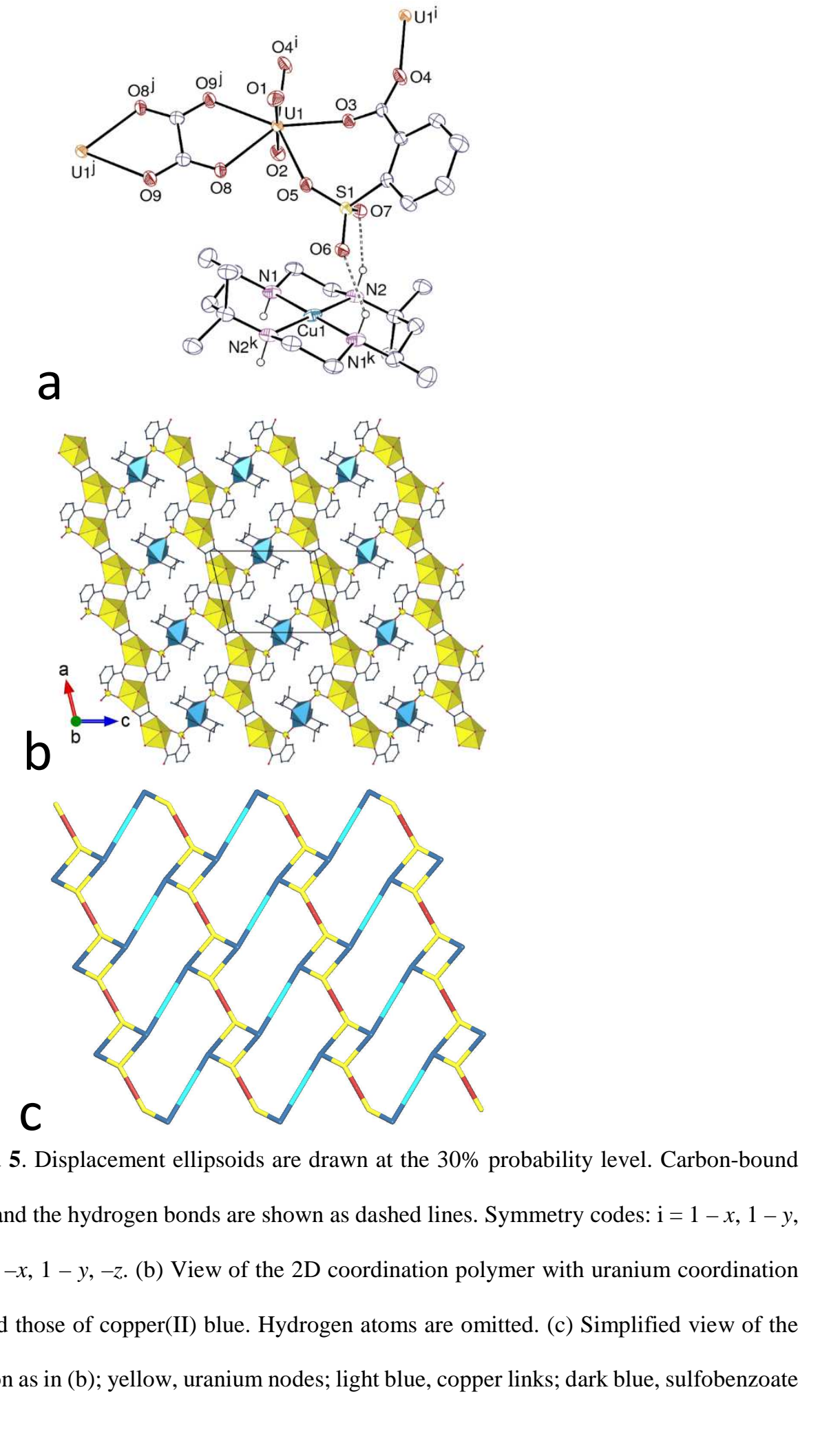
nodes; dark red, oxalate links. 


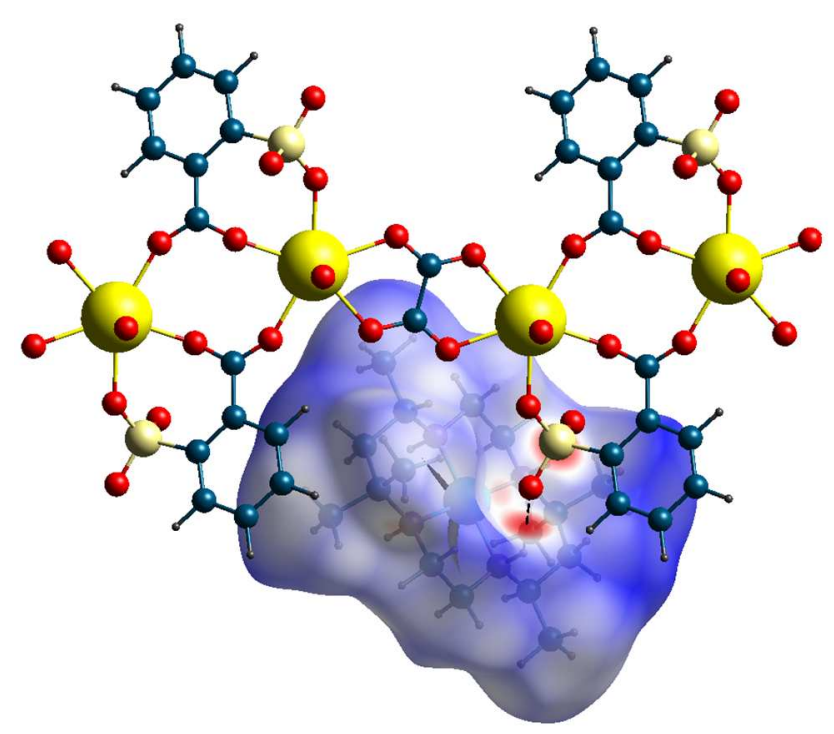

Fig. 7 Hirshfeld surface of the $\left[\mathrm{Cu}\left(R, S-\mathrm{Me}_{6} \text { cyclam }\right)\right]^{2+}$ counterion in complex 5 mapped with $d_{\text {norm }}$, showing the weak red spot corresponding to the $\mathrm{Cu} 1 \cdots \mathrm{O} 6$ interaction, and the larger spots associated to hydrogen bonding interactions. Red spots correspond to distances shorter than the sum of van der Waals radii. The hydrogen bond is shown as a dashed line.

In $\left[\mathrm{PPh}_{4}\right]_{2}\left[\left(\mathrm{UO}_{2}\right)_{2}(2-\mathrm{SB})_{3}\left(\mathrm{H}_{2} \mathrm{O}\right)\right] \cdot \mathrm{H}_{2} \mathrm{O}(\mathbf{6})$, substitution of a spherical, multiple aromatic$\mathrm{CH}$-donor for the discoidal, multiple $\mathrm{NH}$-donor and Lewis acidic metal ion complexes present in 1-5 has a marked effect on the composition and structure of the crystalline material isolated, but the uranyl complex unit present does have some close similarities to those seen in these other species. The asymmetric unit contains four uranyl cations, six 2-SB ${ }^{2-}$ ligands, and four $\mathrm{PPh}_{4}{ }^{+}$counterions (Fig. 8). Atoms U1 and U2 are both chelated by two 2-SB ${ }^{2-}$ ligands in the $\kappa^{1}-O(S) ; \kappa^{1}-O(C)$ mode and they form a $\left[\mathrm{UO}_{2}(2-\mathrm{SB})_{2}\right]_{2}$ dinuclear subunit analogous to those found in complexes 3-5; in contrast, atoms U3 and U4 are chelated by only one ligand, and bound to two carboxylate donors and one water molecule and they form a second kind of dinuclear subunit, $\left[\mathrm{UO}_{2}(2-\mathrm{SB})\left(\mathrm{H}_{2} \mathrm{O}\right)\right]_{2}[\mathrm{U}-\mathrm{O}$ (oxido) 1.755(3)-1.769(3) $\AA$, U-O(carboxylate)

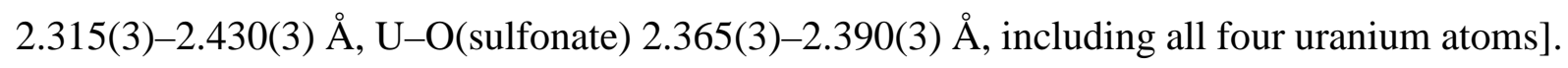






Fig. 8 (a) View of compound 6. Displacement ellipsoids are drawn at the 50\% probability level. Solvent molecules and carbon-bound hydrogen atoms are omitted, and the hydrogen bonds are shown as dashed lines. Symmetry codes: $\mathrm{i}=x-1, y, z+1 ; \mathrm{j}=x+1, y, z-1$. (b) View of the $1 \mathrm{D}$ coordination polymer, the sequence shown corresponding to $\mathrm{U} 1 \cdots \mathrm{U} 2 \cdots \mathrm{U} 3 \cdots \mathrm{U} 4 \cdots \mathrm{U} 1 \cdots \mathrm{U} 2$. (c) View of the packing with uranium coordination polyhedra colored yellow, and solvent molecules and hydrogen atoms omitted.

These two kinds of subunits are connected through single carboxylate bridges involving the otherwise uncoordinated carboxylate oxygen atoms of the simple chelate ligands of the first unit to form an alternate $1 \mathrm{D}$ ribbon-like chain parallel to [101] . This polymer is reinforced by hydrogen bonding interactions of the water ligands with the sulfonate and carboxylate groups of neighbouring subunits $\left[\mathrm{O} \cdots \mathrm{O} 2.734(4)-3.930(4) \AA ̊ \mathrm{O}-\mathrm{H} \cdots \mathrm{O} 112-171^{\circ}\right]$, as well as by 
uncoordinated water interactions with uranyl oxido and sulfonate groups. These chains are further arranged into sheets parallel to (101), separated from one another by layers of $\mathrm{PPh}_{4}^{+}$ cations. The four inequivalent phosphonium cations in any given sheet are involved in a variety of interactions, those involving $\mathrm{P} 2$ and $\mathrm{P} 3$, for example, forming an embrace pair ${ }^{60}$ with a P...P distance of 5.8088(18) $\AA$, while also being involved, as is typical of such cations, ${ }^{24,26,27}$ in multiple $\mathrm{CH} \cdots \mathrm{O}$ interactions with the anionic polymer chains and one uncoordinated water molecule. The combined $\mathrm{CH} \cdots \mathrm{O}$ interactions of all cations lead to the formation of a $3 \mathrm{D}$ network (KPI 0.67, with solvent included), which may also be stabilized by numerous $\pi$ stacking interactions [shortest centroid ‥centroid distance 3.587(4) $\AA$, for sulfobenzoate ligands

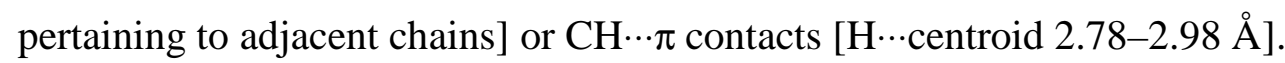

p-Sulfonatocalix[4]arene complexes. Although obtained from a reaction mixture containing uranyl ions, the compound $\left[\left\{\mathrm{Cu}\left(R, S-\mathrm{Me}_{6} \mathrm{cyclam}\right)\right\}_{5}\left(\mathrm{H}_{3} \mathrm{C} 4 \mathrm{~S}\right)_{2}\right] \cdot 17 \mathrm{H}_{2} \mathrm{O}(7)$, shown in Fig. 9, proved to be just a complex of the $\mathrm{Cu}^{\mathrm{II}}$ macrocyclic cation with the penta-anion of $p$ sulfonatocalix[4]arene, a common anion with one phenolic and four sulfonic acid groups deprotonated, which appears in more than 60 crystal structures reported in the CSD. The high degree of hydration of the crystals gives rise to a complicated hydrogen bonded network in the lattice, such networks being rather characteristic of derivatives of this calixarene, ${ }^{5}$ but the primary interest here is the nature of the sulfonate interactions with the $\left[\mathrm{Cu}\left(R, S-\mathrm{Me}_{6} \text { cyclam }\right)\right]^{2+}$ cations and how they compare with those seen in complexes $\mathbf{4}$ and $\mathbf{5}$. Within the lattice of $\mathbf{7}$, there are 3 inequivalent $\left[\mathrm{Cu}\left(R, S-\mathrm{Me}_{6} \text { cyclam) }\right]^{2+}\right.$ moieties (one of them centrosymmetric), all of which have different sulfonate environments. $\mathrm{Cu} 1$ appears to be 5-coordinate, with a relatively short $\mathrm{Cu} \cdots \mathrm{O}$ contact $[\mathrm{Cu} 1-\mathrm{O} 12.3698(18) \AA]$ but one again accompanied by a short $\mathrm{NH} \cdots \mathrm{O}$ 

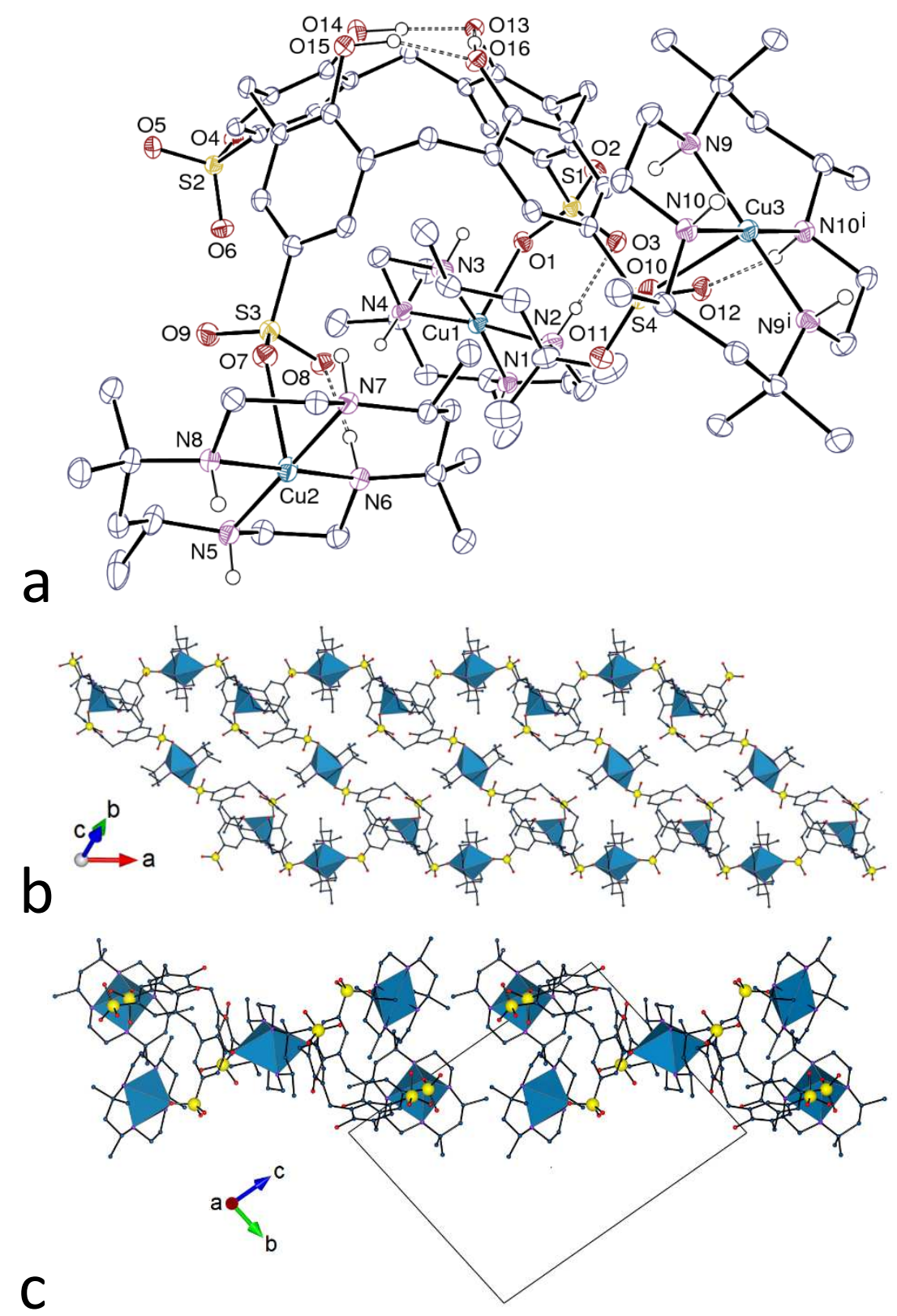

Fig. 9 (a) View of compound 7. Displacement ellipsoids are drawn at the $40 \%$ probability level. Solvent molecules and carbon-bound hydrogen atoms are omitted, and the hydrogen bonds are shown as dashed lines. Symmetry code: $\mathrm{i}=2-x, 1-y,-z$. (b) View of the 1D ribbon-like chain with copper(II) coordination polyhedra colored blue. (c) Two chains viewed end-on. Solvent molecules and hydrogen atoms are omitted in the last two views.

interaction $\left[\mathrm{N} 2 \cdots \mathrm{O} 32.870(3) \AA, \mathrm{N} 2-\mathrm{H} \cdots \mathrm{O} 3158^{\circ}\right]$. On the face of the macrocyclic complex of $\mathrm{Cu} 1$ where there is no nearby sulfonate entity, two water molecules are involved in hydrogen

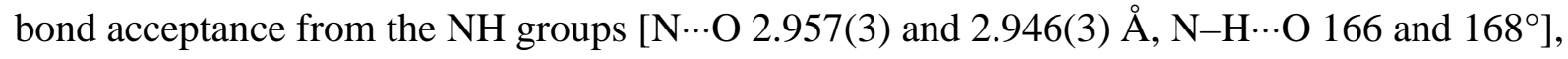


with the HS providing no evidence that either water molecule could be considered to be coordinated to the metal ion. $\mathrm{Cu} 2$ adopts unsymmetrical 6-coordination, with the $\mathrm{HS}$ at the $\mathrm{Cu}-$ $\mathrm{O}$ axis showing a relatively slight perturbation compared to those due to adjacent $\mathrm{NH} \cdots \mathrm{O}$ interactions. Both Cu2-O bonds [Cu2-O $4^{\mathrm{j}} 2.5905(17) \AA$ and $\mathrm{Cu} 2-\mathrm{O} 72.5062(17) \AA$; symmetry code: $\mathrm{j}=x+1, y, z]$ are accompanied by $\mathrm{NH} \cdots \mathrm{O}$ bonds involving the same sulfonate groups

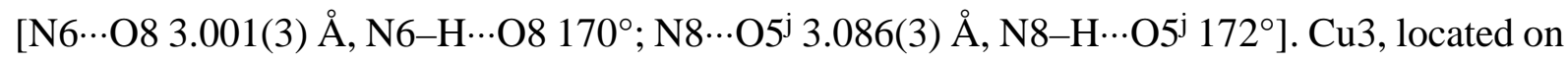

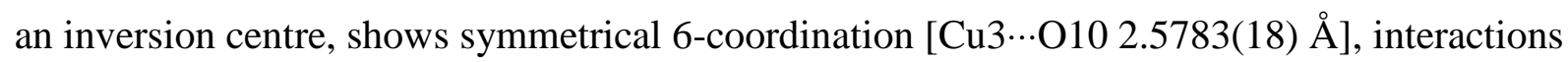

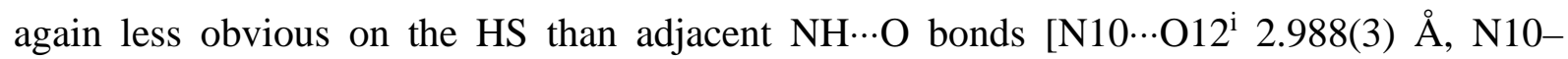
$\mathrm{H} \cdots \mathrm{O} 12^{\mathrm{i}} 166^{\circ}$; symmetry code: $\left.\mathrm{i}=2-x, 1-y,-z\right]$. Overall, the greater range in $\mathrm{Cu}-\mathrm{O}$ distances than in $\mathrm{NH} \cdots \mathrm{O}$ indicates that hydrogen bonding effects must dominate those of coordination, although the difference may not be large. The polymeric arrangement formed is $1 \mathrm{D}$ and ribbonlike, and running along the $a$ axis. $\mathrm{Cu} 2, \mathrm{Cu} 3$ and $\mathrm{H}_{3} \mathrm{C}_{4} \mathrm{~S}^{5-}$ are nodes and $\mathrm{Cu} 1$ is a decorating group only, the point symbol being $\left\{8^{2} .12\right\}_{2}\{8\}_{3}$. The chains are further arranged into layers

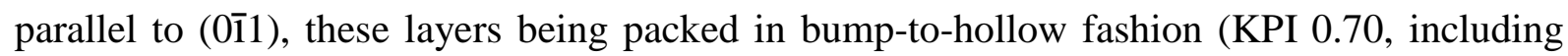
solvent molecules). In spite of repeated attempts, no uranyl complex with $p$ sulfonatocalix $[4]$ arene including $[\mathrm{Ni}(\mathrm{cyclam})]^{2+},\left[\mathrm{Cu}\left(R, S-\mathrm{Me}_{6} \text { cyclam }\right)\right]^{2+}$ or related species could be obtained, but, in contrast, $\mathrm{PPh}_{4}{ }^{+}$proved to be a suitable cation.

The two complexes $\left[\mathrm{PPh}_{4}\right]_{5}\left[\mathrm{UO}_{2}\left(\mathrm{H}_{4} \mathrm{C} 4 \mathrm{~S}\right)\left(\mathrm{H}_{2} \mathrm{O}\right)_{4}\right]\left[\mathrm{UO}_{2}\left(\mathrm{H}_{3} \mathrm{C} 4 \mathrm{~S}\right)\left(\mathrm{H}_{2} \mathrm{O}\right)_{4}\right] \cdot 14 \mathrm{H}_{2} \mathrm{O}(8)$ and $\left[\mathrm{PPh}_{4}\right]_{3}\left[\mathrm{UO}_{2}\left(\mathrm{H}_{3} \mathrm{C} 4 \mathrm{~S}\right)\left(\mathrm{H}_{2} \mathrm{O}\right)_{3}\right] \cdot 9 \mathrm{H}_{2} \mathrm{O}(\mathbf{9})$, obtained from the same reaction mixture involving uranyl and gadolinium(III) nitrates (the latter cation not included in the complexes), $\mathrm{PPh}_{4}{ }^{+}$ cations, and $\mathrm{H}_{8} \mathrm{C} 4 \mathrm{~S}$, have structures with many features in common with those of analogous lanthanide(III) complexes. ${ }^{5}$ Thus, both lattices are layered, with sheets of uranyl-calixarene complexes separated by sheets of phosphonium cations, the macrocyclic units are all in their cone conformation with one phenyl group of $\mathrm{PPh}_{4}{ }^{+}$cation included in each cavity (although, consistent with the stoichiometry, not all the cations are included), the uranyl cations are present 
in largely hydrated forms with coordinated sulfonate groups being bound through one oxygen only, and both coordinated and lattice water molecules are involved in a complicated hydrogen bonding network. As a species providing a planar array of hydrogen bond-donor coordinated water molecules and a linear hydrogen bond acceptor dioxido unit, however, the uranyl ion is a unique supramolecular synthon and the lattices of $\mathbf{8}$ and $\mathbf{9}$ do show corresponding features. Although uranium in uranyl complexes is known to show equatorial coordination numbers between 4 and 6 (and very rarely 3 and 7), in 8 and $\mathbf{9}$, as in the mixed uranyl-lanthanide species ${ }^{9}$ despite the presence of the small sulfonate chelate ring, a coordination number only of 5 is found, involving one sulfonate oxygen atom and four water molecules in 8 (Fig. 10), and two non-adjacent sulfonate oxygen donors and three water molecules in 9 (Fig. 11). Compound 8 contains two crystallographically independent complex molecules, and $\mathbf{9}$ only one, the UO(sulfonate) bond lengths being 2.332(4) and 2.327(4) $\AA$ in 8, and 2.335(3) and 2.360(3) $\AA$ in 9. In complex $\mathbf{8}$, in which these bonds are shortest (and are in fact shorter than all the uranylsulfonate bonds found in the CSD, which are in the range of 2.34-2.60 $\mathrm{A}$ ), the U-O interaction is accompanied by hydrogen bonding of another sulfonate oxygen atom (on the same sulfur atom) to an adjacent coordinated water molecule $\left[\mathrm{O} 19 \cdots \mathrm{O} 52.755(5) \AA\right.$ A, O19-H…O $161^{\circ}$; $\mathrm{O} 44 \cdots \mathrm{O} 262.983(8) \AA$, $\mathrm{O} 44-\mathrm{H} \cdots \mathrm{O} 26155^{\circ}$ ]. In complex 9, there is no such direct links involving the water ligands, but hydrogen bonding mediated by a single water molecule with oxygen atoms of the two coordinated sulfonate groups is present. The $\mathrm{U}-\mathrm{O}$ distances in these cases are shorter than those found for $\mathrm{U}-\mathrm{O}$ (sulfonate) in any of the complexes of 2-SB ${ }^{2-}$ described herein and of related species, ${ }^{18,20}$ where coordination of the carboxylate can be seen as inducing the sulfonate binding, indicating that the hydrogen bond-induced "chelation" may be a substantial effect. While $\mathbf{8}$ is a discrete, molecular complex, $\mathbf{9}$ crystallizes as a 1D polymer running along $[10 \overline{1}]$ in which the adjacent positions of the coordinated sulfonate groups on the macrocyclic 


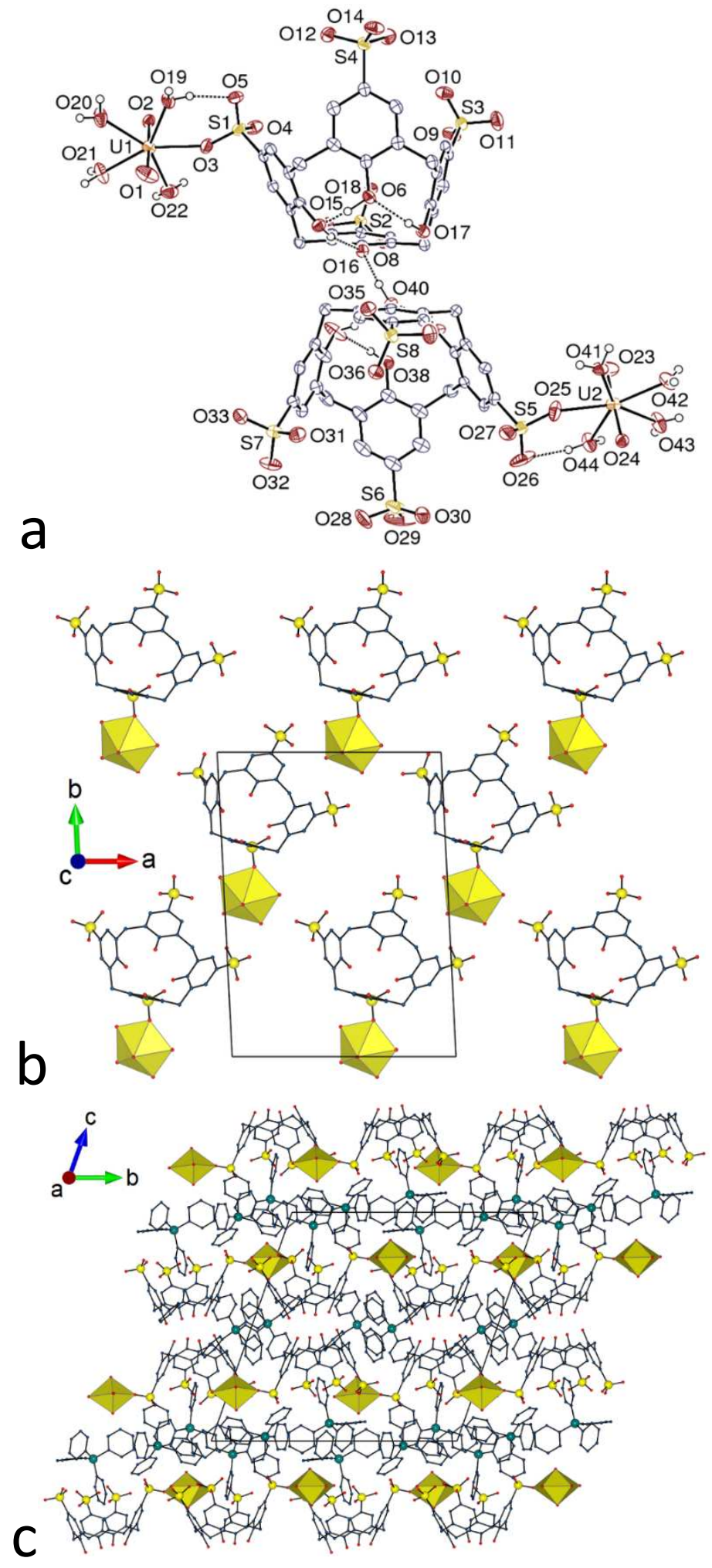

Fig. 10 (a) View of compound 8. Displacement ellipsoids are drawn at the 50\% probability level. Solvent molecules and carbon-bound hydrogen atoms are omitted, and the hydrogen bonds are shown as dashed lines. (b) View of the arrangement of uranyl complexes within a sheet. (c) Packing with sheets viewed edge-on. Solvent molecules and hydrogen atoms are omitted. 

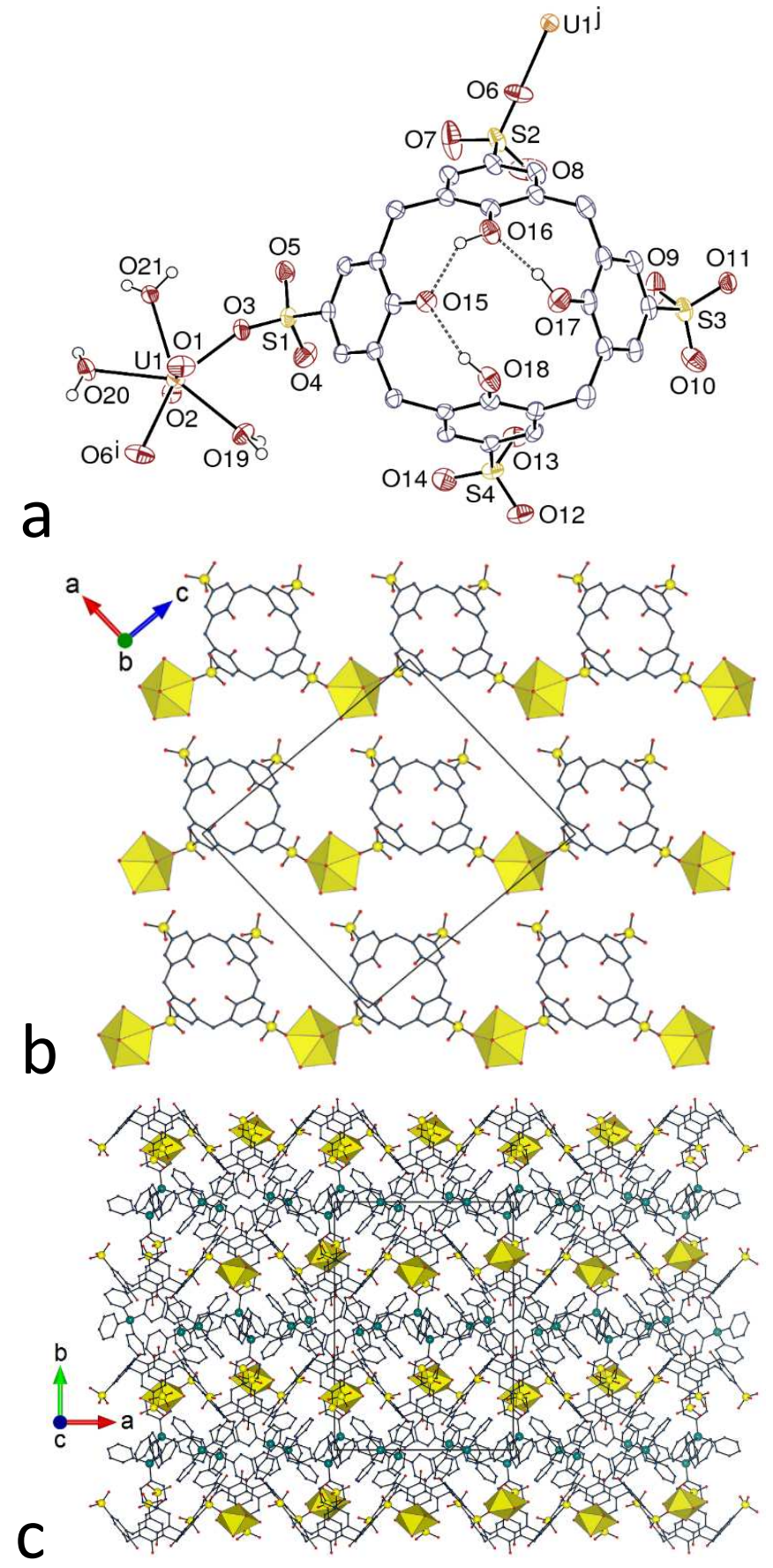

Fig. 11 (a) View of compound 9. Displacement ellipsoids are drawn at the 50\% probability level. Solvent molecules and carbon-bound hydrogen atoms are omitted, and the hydrogen bonds are shown as dashed lines. Symmetry codes: $\mathrm{i}=x+1 / 2,3 / 2-y, z-1 / 2 ; \mathrm{j}=x-1 / 2,3 / 2-y, z+1 / 2$. (b) View of the arrangement of $1 \mathrm{D}$ coordination polymers within a sheet. (c) Packing with sheets viewed edge-on. Solvent molecules and hydrogen atoms are omitted. 
ring result in all the calixarene units pointing on one edge of the ribbon-like assembly, with the calixarene cones alternating in orientation along the chain, and the uranyl cations on the other edge. While the hydrogen bonding interactions of a single water ligand with the calixarene sulfonate groups in $\mathbf{8}$ are of the same form as those found in lanthanide(III) complexes, for the complete uranyl species they result in an essentially planar array of calixarenes about uranium and not in any form of encapsulation of the aqua-cation. Somewhat surprisingly, given the quite extensive known chemistry of uranyl complexes of phenolic calixarenes, ${ }^{61}$ phenoxide donation is not seen in either $\mathbf{8}$ or $\mathbf{9}$ (as it is not in the mixed uranyl-lanthanide complexes). In complex 9, the ligand is in its penta-deprotonated form $\mathrm{H}_{3} \mathrm{C}_{4} \mathrm{~S}^{5-}$, as in $\mathbf{7}$, and the three phenolic protons remaining (one of them disordered) are involved in intramolecular hydrogen bonding $[\mathrm{O} \cdots \mathrm{O}$ 2.487(4)-2.791(4) $\AA$, $\mathrm{O}-\mathrm{H} \cdots \mathrm{O} 137-172^{\circ}$ ]. In complex 8, the two forms $\mathrm{H}_{4} \mathrm{C}_{4} \mathrm{~S}^{4-}$ and $\mathrm{H}_{3} \mathrm{C}_{4} \mathrm{~S}^{5-}$ coexist (the lower concentration of the first in solution possibly accounting for the predominance of complex 9, see Experimental). The phenolic groups in the $\mathrm{H}_{3} \mathrm{C}_{4} \mathrm{~S}^{5-}$ groups of 8 form intramolecular hydrogen bonds, but one of the protons in the tetra-protonated form is

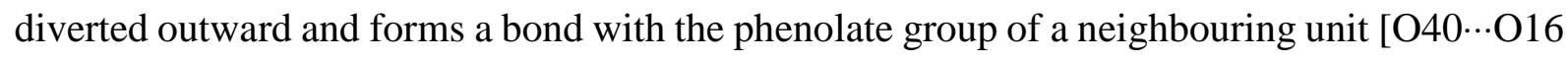
2.478(5) $\AA$, $\mathrm{O} 40-\mathrm{H} \cdots \mathrm{O} 16165^{\circ}$ ], the two interacting molecules being oriented face-to-face. Examination of calixarene structures reported in the CSD shows that such hydrogen bonding between phenolic/ate groups of facing molecules is not particularly frequent, but some examples are found, as with calix[5]arene derivatives, ${ }^{62,63}$ in which, as in the present case, the intermolecular hydrogen bonds seem to be stronger than the intramolecular ones. ${ }^{62}$ As a result of this arrangement, complex $\mathbf{8}$ displays "up-down" orientation of the calixarene units as in "clay-like" derivatives, ${ }^{5}$ with double sheets of hydrogen bonded calixarenes parallel to (001) separated by layers of phosphonium cations (with other cations located within the double layers). It is notable that, in contrast to "clay-like" compounds based on $p$ sulfonatocalix[4]arene, ${ }^{5}$ the layers separating the calixarene sheets are hydrophobic here. In 
complex 9, the chains are linked into a 2D sheet parallel to (010) by hydrogen bonding interactions involving sulfonate plus coordinated and lattice water molecules such that each uranyl centre has four near-neighbour calixarenes in a nearly square array with opposed pairs having the same orientation, these layers being separated from one another by layers of phosphonium cations. As very frequently observed with $p$-sulfonatocalix[4]arene, ${ }^{5,64-66}$ each macrocycle cavity in complex 9 is occupied by a phenyl group of the phosphonium cation

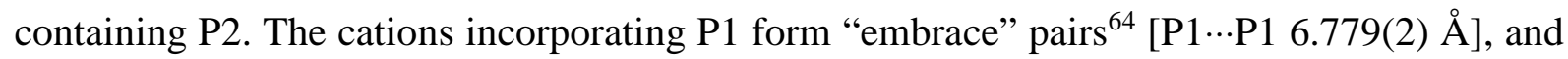

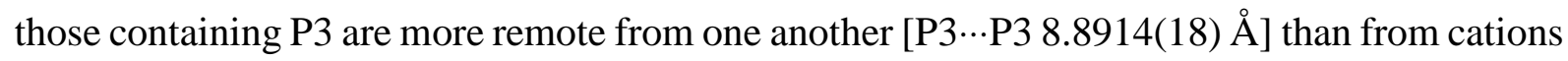

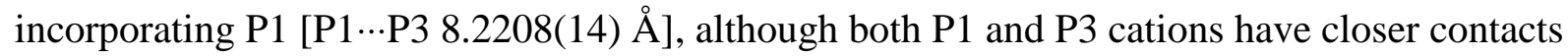


dispersion interactions between the cations. As seen on their HSs, all three inequivalent phosphonium cations are involved to some extent in $\mathrm{CH} \cdots \mathrm{O}$ interactions. In the more complicated lattice of $\mathbf{8}$, where there are 5 inequivalent phosphonium ions and 2 inequivalent uranyl ions, the gross features are similar but the cations within the sheet containing calixarenes oriented such that the phenolic rims are facing each other involve P3 and P4 only, and of course there is no inclusion in the calixarene cavity in this case. Cations incorporating P1, P2 and P5 are located in the sheet separating the double layers, but only P1 and P2 are included, with the orientations of the included phenyl rings being opposite. The packing in both $\mathbf{8}$ and $\mathbf{9}$ is quite compact, with KPIs of 0.68 and 0.70 , respectively (free water molecules included).

The complex $\left[\mathrm{PPh}_{4}\right]_{2}\left[\mathrm{UO}_{2}\left(\mathrm{H}_{4} \mathrm{C} 4 \mathrm{~S}\right)\left(\mathrm{H}_{2} \mathrm{O}\right)_{3}\right] \cdot 11 \mathrm{H}_{2} \mathrm{O}(\mathbf{1 0})$, obtained from a solution devoid of gadolinium(III) nitrate but otherwise identical to that having produced complexes $\mathbf{8}$ and $\mathbf{9}$, 

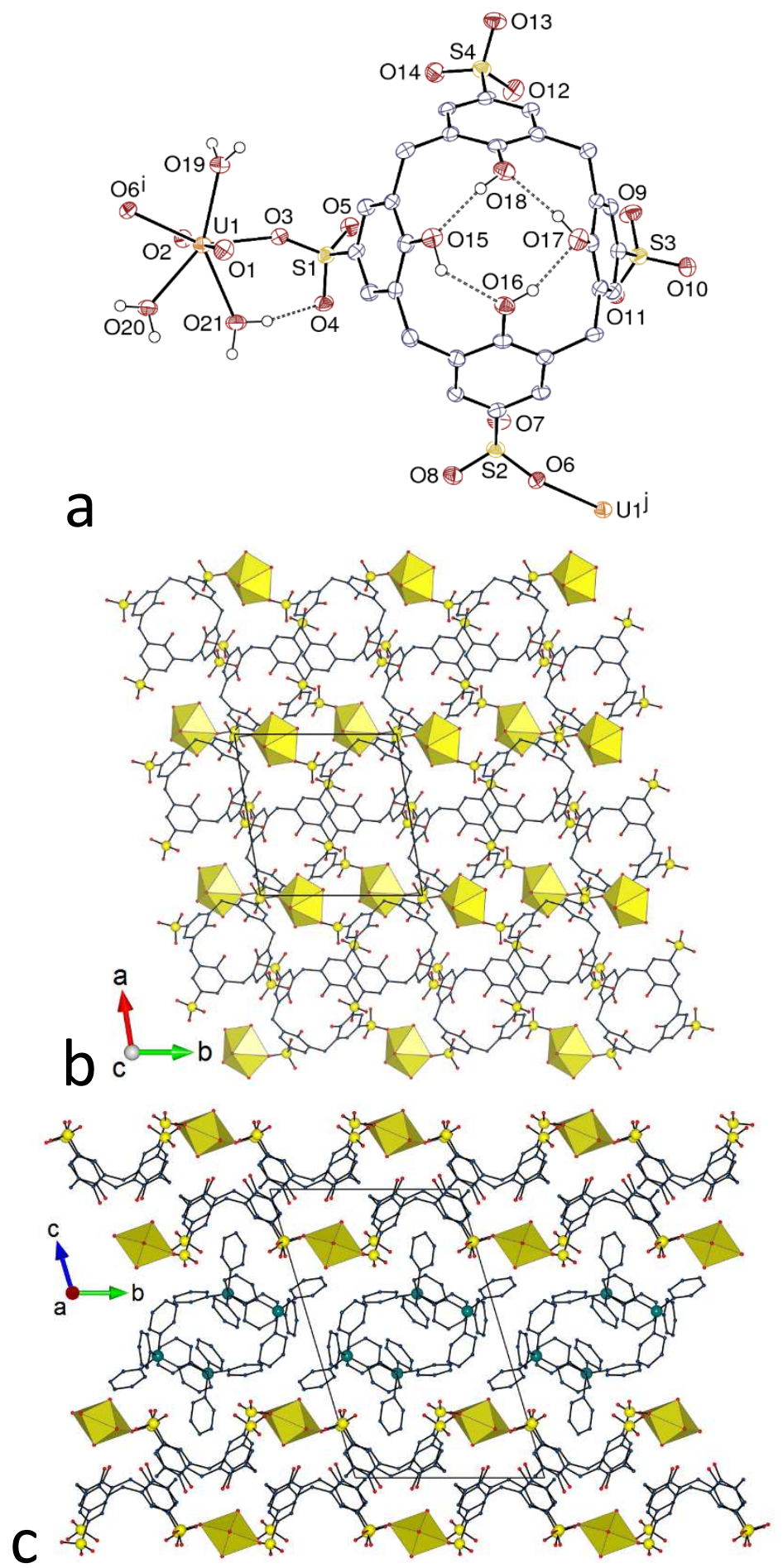

Fig. 12 (a) View of compound 10. Displacement ellipsoids are drawn at the 50\% probability level. Solvent molecules and carbon-bound hydrogen atoms are omitted, and the hydrogen bonds are shown as dashed lines. Symmetry codes: $\mathrm{i}=x, y-1, z ; \mathrm{j}=x, y+1, z$. (b) View of the arrangement of 1D coordination polymers within a double layer. (c) Packing with layers viewed edge-on. Solvent molecules and hydrogen atoms are omitted. 
differs from the latter complexes by including only the tetra-deprotonated form of the ligand, and thus a lesser number of $\mathrm{PPh}_{4}{ }^{+}$counterions. As in $\mathbf{9}$, the asymmetric unit contains a single uranium atom which is bound to two non-adjacent sulfonate oxygen atoms and three water molecules (Fig. 12). The U-O(sulfonate) bond lengths of 2.378(3) and 2.393(3) $\AA$ are slightly larger than those in $\mathbf{8}$ and $\mathbf{9}$, although they are still in the lower part of the range of U$\mathrm{O}$ (sulfonate) bond lengths. Here also, a hydrogen bond links one of the water ligands and an

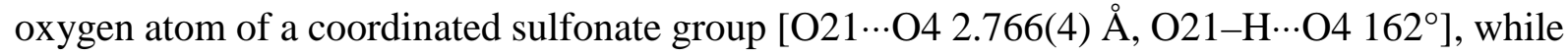
the four phenolic groups are involved in a cyclic intramolecular hydrogen bond array $[\mathrm{O} \cdots \mathrm{O}$ 2.677(4)-2.733(4) $\left.\AA, \mathrm{O}-\mathrm{H} \cdots \mathrm{O} 132-170^{\circ}\right]$. A 1D polymeric chain parallel to the $b$ axis is formed, which is however different from that in $\mathbf{9}$ in that all the calixarene molecules, related by translations, are oriented identically. Not only are these chains arranged in layers parallel to (001), but two such layers with reverse orientations of the calixarene units, and offset with respect to one another, are associated to form a double layer, close to those found in $\left[\mathrm{NMe}_{4}\right]_{2}\left[\mathrm{UO}_{2}\left(\mathrm{H}_{4} \mathrm{C} 4 \mathrm{~S}\right)\right] \cdot 0.5 \mathrm{H}_{2} \mathrm{O},{ }^{9}$ but different to those in $\mathbf{8}$ since there is no face-to-face arrangement of the calixarenes here. As a result of bump-to-hollow packing of the two layers, the width of the double layers in $\mathbf{1 0}(\sim 12 \AA)$ is smaller than in $\mathbf{8}(\sim 16 \AA)$. As a consequence, the small distances between the aromatic rings bound to the coordinated sulfonate groups pertaining to calixarenes in different layers are possibly indicative of $\pi$-stacking interactions [centroid $\cdots$ centroid distances 3.467(2) and 3.734(2) ̊, slippages 0.79 and $1.79 \AA$ ]. Several CH$\pi$ interactions involving hydrogen atoms of the $\mathrm{PPh}_{4}{ }^{+}$cations and aromatic rings from both cations and anions are also found $[\mathrm{H} \cdots$ centroid distances $2.49-2.88 \AA$, C-H $\cdots$ centroid angles $\left.121-175^{\circ}\right]$, as well as, more prominently, an intricate array of $\mathrm{OH} \cdots \mathrm{O}$ and $\mathrm{CH} \cdots \mathrm{O}$ hydrogen bonds. Both phosphonium cations form tight centrosymmetric "embrace" pairs, with P $\ldots \mathrm{P}$ distances of 6.022(2) and 6.006(2) $\AA$. With a KPI of 0.70 (solvent included), the packing contains no significant free space. 


\section{Luminescence properties}

Emission spectra under excitation at $420 \mathrm{~nm}$ were recorded for all uranyl complexes in the solid state. A complete absence of uranyl luminescence was observed for compounds $\mathbf{1}-\mathbf{5}$ and $\mathbf{8}-\mathbf{1 0}$. In the case of $\mathbf{1 - 5}$, this is most probably to be ascribed to the d-block transition metal cations quenching uranyl excitation via energy transfer and nonradiative relaxation pathway, as frequently observed, ${ }^{67}$ or simply to preferential absorption of the $420 \mathrm{~nm}$ radiation by the transition metal, ${ }^{29}$ but the origin of apparent quenching in $\mathbf{8}-\mathbf{1 0}$ is less clear and may be related to the presence of a large number of water molecules, both coordinated and free, providing paths for vibrational quenching by $\mathrm{O}-\mathrm{H}$ oscillators, ${ }^{68}$ or due to redox quenching by the phenolic groups of the calixarene. The water content of the compounds formed under hydrothermal conditions is known to decrease when the temperature increases, as a result of thermodynamic control, ${ }^{69}$ and it is in some cases lower than that found when crystallization occurs at room temperature ${ }^{70}$ which may thus be an advantage for obtaining luminescent species. Only the spectrum of complex 6, shown in Fig. 13 together with the spectrum of uranyl nitrate hexahydrate, displays the usual series of peaks associated with the vibronic progression corresponding to the $S_{11} \rightarrow S_{00}$ and $S_{10} \rightarrow S_{0 v}(v=0-4)$ electronic transitions. ${ }^{71}$ The four main peaks for 6 are at 499, 522, 546, and $573 \mathrm{~nm}$, these positions being in the highest part of the range typical of uranyl carboxylate complexes with five equatorial donors. ${ }^{72}$ The corresponding redshift with respect to uranyl complexes with six equatorial donors is well illustrated by comparison with the spectrum of uranyl nitrate hexahydrate (although not a carboxylate complex), in which the coordination sphere contains two chelating nitrates and two water molecules, ${ }^{73,74}$ and for which the four main peaks are at 486, 508, 532, and $557 \mathrm{~nm}$, i.e. blueshifted by about $14 \mathrm{~nm}$ with respect to those for $\mathbf{6}$. The average vibronic splitting energies for the $S_{10} \rightarrow S_{0 v}$ transitions of $863(17)$ and $874(21) \mathrm{cm}^{-1}$ for 6 and $\mathrm{UO}_{2}\left(\mathrm{NO}_{3}\right)_{2} \cdot 6 \mathrm{H}_{2} \mathrm{O}$, 
respectively, are in the usual range. ${ }^{72}$ The solid-state photoluminescence quantum yield (PLQY) for 6 is $0.030 \pm 0.001$. Such low values have previously been found in other uranyl carboxylate complexes having a pale yellow color; ${ }^{28}$ larger values, often associated with green coloring, are still unusual $^{75,76}$ (for comparison, the PLQY of uranyl nitrate hexahydrate measured under the same conditions is $24 \%$ ).



Fig. 13 Emission spectra of compound 6 and uranyl nitrate hexahydrate, recorded in the solid state at room temperature, under excitation at a wavelength of $420 \mathrm{~nm}$.

\section{Conclusions}

We have reported here the synthesis and crystal structure of nine uranyl sulfonate complexes with ligands pertaining to two very different families, 2-, 3- and 4-sulfobenzoates on the one hand, and $p$-sulfonatocalix[4]arene on the other hand. Bulky counterions, $[\mathrm{Ni}(\text { cyclam })]^{2+}$, 
$\left[\mathrm{Cu}\left(R, S-\mathrm{Me}_{6} \text { cyclam }\right)\right]^{2+}$ and $\mathrm{PPh}_{4}{ }^{+}$, were included, although the metal cations did not give a crystalline uranyl complex in the case of the calixarene ligand. In the case of sulfobenzoates, the present results confirm the previously found tendency for the sulfonate group to be bound to the uranyl ion only when $\kappa^{1}-O(S) ; \kappa^{1}-O(C)$ chelation is possible, i.e. with $2-\mathrm{SB}^{2-}$ only. In contrast to the molecular species obtained with the 3- and 4-SB ${ }^{2-}$ ligands, those with 2-SB ${ }^{2-}$ crystallize as $0 \mathrm{D}, 1 \mathrm{D}$ or $2 \mathrm{D}$ species, depending on the counterions, with six-coordinate $\mathrm{Ni}{ }^{\mathrm{II}}$ or $\mathrm{Cu}^{\mathrm{II}}$ cations bridging uranyl-containing subunits in the latter case. Monodentate sulfonate coordination only is present in the complexes with $p$-sulfonatocalix[4]arene, the phenolic/ate groups being uncoordinated and involved in hydrogen bonding only. These calixarenecontaining complexes crystallize as molecular or 1D species, and different kinds of layered packings are found, one of them an original "up-down" bilayer with hydrogen bonding between the lower rims of facing macrocycles. All these results suggest that the complexing ability of the three functional groups found in these ligands toward uranyl ion vary in the order carboxylate $>$ sulfonate $>$ phenol(ate). However, it should be remembered that the sulfobenzoate complexes were obtained under (solvo-)hydrothermal conditions, whereas the $p$ sulfonatocalix[4]arene complexes were synthesized at room temperature, a difference which may have a bearing on this order, particularly concerning the complexation of phenolate groups (it is notable that a case was reported in which crystallization of a complex with 5-sulfosalicylic acid at room temperature even favored sulfonate over carboxylate coordination ${ }^{21}$ ). Unsulfonated calixarenes are of course well known to produce (non-luminescent) phenoxide complexes with uranyl ion. ${ }^{61}$ Unfortunately, no complex with $p$-sulfonatocalix[4]arene could be isolated from hydrothermal synthesis attempts.

Hydrogen bonding involving $\mathrm{OH}$ (water) and $\mathrm{NH}$ (macrocycles) groups as donors are a dominant component of the weak interactions found in these compounds, with the sulfonate 
groups being frequent acceptors. While hydrogen bonding of coordinated sulfonates is well recognised in a wide variety of metal ion complexes, ${ }^{1-5,77}$ less attention has been given to the influence such hydrogen bonding may have upon coordinative interactions. In the present instances involving $\mathrm{Ni}^{\mathrm{II}}$ and $\mathrm{Cu}^{\mathrm{II}}$ complexes of tetraazamacrocycles, $\mathrm{NH} \cdots \mathrm{O}$ (sulfonate) bonding is associated with a very weak to only moderately strong coordination of adjacent sulfonate oxygen atoms. In two of the three uranyl ion complexes of $p$-sulfonatocalix[4]arene presently characterised, however, $\mathrm{OH}\left(\right.$ coordinated water) $\cdots \mathrm{O}$ (sulfonate) bonding is associated with $\mathrm{U}_{-}$ $\mathrm{O}$ (sulfonate) bond distances which belie the regard of sulfonate as a weak ligand. It thus appears that, although isolated sulfonate complexation to uranyl is possible, as shown in one of the calixarene complexes reported here as well as in previous cases, ${ }^{9,17,19,21}$ it is nevertheless often associated with other coordination or hydrogen bonding interactions inducing a geometry favorable to the formation of a metal-sulfonate link. It is also notable that sulfonate complexation to uranyl is found in the presence of water as potential ligand, although the latter is considered to have an unfavorable effect on sulfonate complexation. ${ }^{1-4}$

Uranyl luminescence is completely absent in all the heterometallic complexes, and also in the complexes with $p$-sulfonatocalix[4]arene, in which case it may be due to the large number of water molecules present. Only one 2-sulfobenzoate complex with $\mathrm{PPh}_{4}{ }^{+}$counterions displays well-resolved emission in the solid state, albeit with a low quantum yield of $3 \%$.

\section{Conflicts of interest}

There are no conflicts of interest to declare. 


\section{References}

1. A. P. Côté and G. K. H. Shimizu, Coord. Chem. Rev., 2003, 245, 49.

2. J. Cai, Coord. Chem. Rev., 2004, 248, 1061.

3. V. Videnova-Adrabinska, Coord. Chem. Rev., 2007, 251, 1987.

4. G. K. H. Shimizu, R. Vaidhyanathan and J. M. Taylor, Chem. Soc. Rev., 2009, 38, 1430.

5. I. Ling and C. L. Raston, Coord. Chem. Rev., 2018, 375, 80.

6. J. P. Guthrie, Can. J. Chem., 1978, 56, 2342-2354.

7. R. D. Hancock and A. E. Martell, Chem. Rev., 1989, 89, 1875.

8. J. Harrowfield and P. Thuéry, Dalton Trans., 2017, 46, 11533.

9. P. Thuéry, CrystEngComm, 2012, 14, 6369.

10. A. S. Wilson, Acta Crystallogr., Sect. B, 1978, 34, 2302.

11. N. W. Alcock, T. J. Kemp and J. Leciejewicz, Inorg. Chim. Acta, 1993, 203, 81.

12. J. C. Berthet, M. Lance, M. Nierlich and M. Ephritikhine, Eur. J. Inorg. Chem., 2000, 1969.

13. G. B. Andreev, N. A. Budantseva, I. G. Tananaev and B. F. Myasoedov, Acta Crystallogr., Sect. E, 2007, 63, m3159.

14. P. Thuéry, Cryst. Growth Des., 2011, 11, 3282.

15. P. Thuéry, Cryst. Growth Des., 2011, 11, 5702.

16. U. Betke, K. Neuschulz and M. S. Wickleder, Chem. Eur. J., 2011, 17, 12784.

17. P. Thuéry, CrystEngComm, 2012, 14, 3363.

18. P. Thuéry, Inorg. Chem., 2013, 52, 435.

19. P. Thuéry, CrystEngComm, 2013, 15, 2401.

20. W. Yang, T. Tian, H. U. Wu, Q. J. Pan, S. Dang and Z. M. Sun, Inorg. Chem., 2013, 52, 2736.

21. P. Thuéry, Eur. J. Inorg. Chem., 2014, 58.

22. P. Thuéry and J. Harrowfield, Eur. J. Inorg. Chem., 2017, 978. 
23. P. Thuéry, Eur. J. Inorg. Chem., 2017, 2876.

24. P. Thuéry, Y. Atoini and J. Harrowfield, Cryst. Growth Des., 2018, 18, 2609.

25. P. Thuéry and J. Harrowfield, Cryst. Growth Des., 2018, 18, 5512.

26. P. Thuéry, Y. Atoini and J. Harrowfield, Inorg. Chem., 2018, 57, 6283.

27. P. Thuéry, Y. Atoini and J. Harrowfield, Inorg. Chem., 2018, 57, 7932.

28. P. Thuéry, Y. Atoini and J. Harrowfield, Inorg. Chem., 2019, 58, 567.

29. P. Thuéry, Y. Atoini and J. Harrowfield, Inorg. Chem., 2019, 58, 870.

30. K. X. Wang and J. S. Chen, Acc. Chem. Res., 2011, 44, 531.

31. M. B. Andrews and C. L. Cahill, Chem. Rev., 2013, 113, 1121.

32. T. Loiseau, I. Mihalcea, N. Henry and C. Volkringer, Coord. Chem. Rev., 2014, 266-267, 69.

33. J. Su and J. S. Chen, Struct. Bond., 2015, 163, 265.

34. P. Thuéry and J. Harrowfield, Dalton Trans., 2017, 46, 13660.

35. M. J. Horner, K. T. Holman and M. D. Ward, J. Am. Chem. Soc., 2007, 129, 14640.

36. K. T. Holman, A. M. Pivovar, J. A. Swift and M. D. Ward, Acc. Chem. Res., 2001, 34, 107.

37. A. M. Tait, D. H. Busch and N. F. Curtis, Inorganic Syntheses, 1978, 18, 10.

38. R. W. W. Hooft, COLLECT, Nonius BV: Delft, The Netherlands, 1998.

39. Z. Otwinowski and W. Minor, Methods Enzymol., 1997, 276, 307.

40. G. M. Sheldrick, Acta Crystallogr., Sect. A, 2015, 71, 3.

41. G. M. Sheldrick, Acta Crystallogr., Sect. C, 2015, 71, 3.

42. A. L. Spek, Acta Crystallogr., Sect. C, 2015, 71, 9.

43. L. J. Farrugia, J. Appl. Crystallogr., 2012, 45, 849.

44. K. Momma and F. Izumi, J. Appl. Crystallogr., 2011, 44, 1272.

45. V. A. Blatov, Struct. Chem., 2012, 23, 955.

46. K. E. Knope, D. T. de Lill, C. E. Rowland, P. M. Cantos, A. de Bettencourt-Dias and C. L. Cahill, Inorg. Chem., 2012, 51, 201. 
47. M. B. Andrew and C. L. Cahill, CrystEngComm, 2011, 13, 7068.

48. K. E. Knope, H. Kimura, Y. Yasaka, M. Nakahara, M. B. Andrews and C. L. Cahill, Inorg. Chem., 2012, 51, 3883.

49. P. Thuéry and J. Harrowfield, Inorg. Chem., 2015, 54, 8093.

50. G. Demazeau, Z. Naturforsch., 2010, 65b, 999.

51. C. M. Zakaria, G. Ferguson, A. J. Lough and C. Glidewell, Acta Crystallogr., Sect. B, 2002, 58, 78.

52. M. A. Spackman and D. Jayatilaka, CrystEngComm, 2009, 11, 19.

53. S. K. Wolff, D. J. Grimwood, J. J. McKinnon, M. J. Turner, D. Jayatilaka and M. A. Spackman, CrystalExplorer; University of Western Australia: Crawley, Australia, 2012.

54. A. L. Spek, Acta Crystallogr., Sect. D, 2009, 65, 148.

55. P. Gilli, L. Pretto, V. Bertolasi and G. Gilli, Acc. Chem. Res., 2009, 42, 33.

56. C. R. Groom, I. J. Bruno, M. P. Lightfoot and S. C. Ward, Acta Crystallogr., Sect. B, 2016, 72, 171.

57. R. Taylor and O. Kennard, J. Am. Chem. Soc., 1982, 104, 5063.

58. G. R. Desiraju, Acc. Chem. Res., 1996, 29, 441.

59. A. Zitolo, G. Chillemi and P. D'Angelo, Inorg. Chem., 2012, 51, 8827.

60. M. Scudder and I. Dance, J. Chem. Soc., Dalton Trans., 1998, 3167.

61. P. Thuéry, M. Nierlich, J. Harrowfield and M. I. Ogden, in Calixarenes 2001, Z. Asfari, V. Böhmer, J. Harrowfield, J. Vicens, Eds., Ch. 30, p. 561, Kluwer Academic Publishers: Dordrecht, The Netherlands, 2001.

62. S. E. Biali, V. Böhmer, I. Columbus, G. Ferguson, C. Grüttner, F. Grynszpan, E. F. Paulus and I. Thondorf, J. Chem. Soc., Perkin Trans. 2, 1998, 2261.

63. C. Gargiulli, G. Gattuso, A. Notti, F. Nicoló and A. Pappalardo, Acta Crystallogr., Sect. E, 2012, 68, o3423. 
64. M. Makha, C. L. Raston, A. N. Sobolev and A. H. White, Chem. Commun., 2004, 1066.

65. P. J. Nichols, M. Makha and C. L. Raston, Cryst. Growth Des., 2006, 6, 1161.

66. M. Makha, Y. Alias, C. L. Raston and A. N. Sobolev, New J. Chem., 2007, 31, 662.

67. A. T. Kerr and C. L. Cahill, Cryst. Growth Des., 2014, 14, 1914.

68. L. S. Natrajan, Coord. Chem. Rev., 2012, 256, 1583.

69. A. K. Cheetham, C. N. R. Rao and R. K. Feller, Chem. Commun., 2006, 4780.

70. P. Thuéry, Inorg. Chem. Commun., 2009, 12, 800.

71. A. Brachmann, G. Geipel, G. Bernhard and H. Nitsche, Radiochim. Acta, 2002, 90, 147.

72. P. Thuéry and J. Harrowfield, Inorg. Chem., 2017, 56, 13464.

73. D. Hall, A. D. Rae and T. N. Waters, Acta Crystallogr., 1965, 19, 389.

74. J. C. Taylor and M. H. Mueller, Acta Crystallogr., 1965, 19, 536.

75. J. Xie, Y. Wang, W. Liu, X. Lin, L. Chen, Y. Zou, J. Diwu, Z. Chai, T. E. Albrecht-Schmitt, G. Liu and S. Wang, Angew. Chem. Int. Ed., 2017, 56, 7500.

76. Y. Wang, X. Yin, W. Liu, J. Xie, J. Chen, M. A. Silver, D. Sheng, L. Chen, J. Diwu, N. Liu, Z. Chai, T. E. Albrecht-Schmitt and S. Wang, Angew. Chem. Int. Ed., 2018, 57, 7883.

77. Z. M. Sun, J. G. Mao, Y. Q. Sun, H. Y. Zeng and A. Clearfield, Inorg. Chem., 2004, 43, 336. 
For Table of Contents Use Only

The sulfonate group as a ligand: a fine balance between hydrogen bonding and metal ion coordination in uranyl ion complexes

Pierre Thuéry, Youssef Atoini and Jack Harrowfield



Nine uranyl sulfonate complexes display various association modes of the sulfonate groups, either coordinating or acting as hydrogen bond acceptors. 